\title{
20 años de control de fusiones y adquisiciones en Argentina (1999-2019): Indicadores de desempeño.
}

\author{
Juliana Cardinale ${ }^{1}$, Diego Petrecolla², Carlos Romero 3
}

\section{Resumen}

Este trabajo presenta los resultados del análisis estadístico de las fusiones y adquisiciones ( $F \& A$ ) evaluadas por la autoridad de competencia de Argentina, desde el inicio del control de F\&A (a finales de 1999) hasta 2019. En particular, se analiza la evolución de la cantidad de casos con diversas desagregaciones y chequeos cruzados según la naturaleza de las operaciones (horizontal, vertical y de conglomerado), el resultado de la evaluación (autorización, su denegación o condicionamiento), el sector económico afectado y la duración de los trámites. El análisis desarrollado permite obtener indicadores cuantitativos del control de fusiones, y brinda resultados y conclusiones de utilidad, tanto desde el punto de vista de las firmas que planeen operaciones, como para la evaluación de desempeño y el diseño de políticas públicas.

Palabras claves: Antitrust, fusiones y adquisiciones, indicadores cuantitativos.

\section{Abstract}

This paper presents a statistical analysis of the mergers and acquisitions (M\&A) evaluated by the Argentinean competition authority, from 1999 to 2019. In particular, we analyze the evolution of the quantity of cases using different classifications and cross checks in accordance with the nature of the operations (horizontal, vertical, conglomerate), the result of the evaluation (authorization, its denial or conditioning), the economic sector affected and the duration of the procedures. The analysis developed allows us to obtain quantitative indicators of the merger control and produces results and conclusions useful, both from the perspective of firms planning operations in Argentina and for the performance evaluation and design of public policies.

Keywords: Antitrust, mergers and acquisitions, quantitative indicators.

JEL: K21, L40

DOI: https://doi.org/10.46553/ensayos.3.2.2020.p1-36

Fecha de recepción: 08/06/2020; Fecha de aceptación: 20/07/2020

\footnotetext{
${ }^{1}$ National University of Singapore, Faculty of Law, Centre for Legal Theory.

Email: Juliana.cardinale@gmail.com

2 Universidad de Buenos Aires. Facultad de Ciencias Económicas, Departamento de Economía Email: diego.petrecolla@gmail.com

${ }^{3}$ Universidad de Buenos Aires. Facultad de Ciencias Económicas. Departamento de Economía. CONICETUniversidad de Buenos Aires. Instituto Interdisciplinario de Economía Política de Buenos Aires.

Email: carlos.adrian.romero@gmail.com
} 


\section{Introducción}

El presente trabajo expone los resultados del análisis estadístico de las operaciones de fusiones y adquisiciones (F\&A) evaluadas por la autoridad de competencia de Argentina, desde el inicio del control de F\&A (a finales de 1999) hasta 2019. En particular, se analiza la evolución de la cantidad de casos con diversas desagregaciones y chequeos cruzados según la naturaleza de las operaciones (horizontal, vertical y de conglomerado), el resultado de la evaluación (autorización, su denegación o condicionamiento), el sector económico afectado y la duración de los trámites. El análisis desarrollado permite obtener indicadores cuantitativos del control de fusiones, y brinda resultados y conclusiones de utilidad, tanto desde el punto de vista de las empresas del sector privado que planeen operaciones, como para la evaluación del desempeño y el diseño de las políticas públicas.

El objetivo principal de la autoridad de defensa de la competencia argentina, la Comisión Nacional de Defensa de la Competencia (CNDC), es defender el interés económico general, generar una mejor asignación de recursos y proteger el bienestar de los consumidores. El control de F\&A es una pieza fundamental para alcanzar dicho objetivo. Este evalúa el cambio sobre las condiciones de competencia que se produce luego de una operación de concentración económica. Las decisiones y el desempeño de la CNDC funcionan como señal para las empresas del sector privado que quieren hacer inversiones en la Argentina. Si el análisis de las concentraciones económicas evalúa erróneamente las condiciones de competencia en el mercado involucrado o se extiende mucho en el tiempo, esto podría disuadir a las empresas a no realizar transacciones que pudiesen resultar en ganancias de eficiencia e innovaciones.

En este contexto, el presente trabajo es, por un lado, un aporte para las empresas del sector privado que quisiesen hacer una operación de concentración económica. Por otro lado, permite evaluar el desempeño de la CNDC a lo largo de estos últimos 20 años.

La Ley $\mathrm{N}^{\circ} 27.442$ de defensa de la competencia en Argentina, en su artículo 14, establece un plazo máximo de 45 días hábiles administrativos para decidir sobre el resultado de una solicitud de autorización para una operación de concentración económica. En los casos donde la autoridad considere que existan posibles riesgos para la competencia, el plazo puede extenderse hasta 120 días adicionales para la emisión de la resolución. Transcurrido dicho plazo la operación queda autorizada en forma tácita. En el trabajo, se computó la duración del trámite mediante días corridos entre la fecha de notificación y la de resolución. A partir del análisis correspondiente al periodo 1999-2019, se encontró una duración promedio de los trámites de 478 días corridos. El año 2016 fue el que evidenció la mayor duración promedio (1.113 días corridos). Estos valores se alejan notablemente de lo establecido por la ley y deja abierta la pregunta sobre la eficiencia de la CNDC en el control de operaciones de concentración económica. Asimismo, estos valores se alejan notablemente de los observados en otros países de la región como Brasil y Chile. 
Este tipo de análisis y estudios son generalmente realizados por las propias autoridades de competencia de los distintos países ${ }^{4}$, organismos internacionales y revisiones de pares llevadas a cabo por organismos internacionales como la $\mathrm{OECD}^{5}$ y la UNCTAD $^{6}$. En la Argentina en particular, el único antecedente al tema es Greco et al. (2013), donde el análisis se corresponde al periodo comprendido entre 1999 y 2011 . El presente trabajo es una actualización y revisión de este último, cubriendo hasta el año 2019. La base de datos que se construye a partir de este tipo de trabajos sirve para futuros análisis cuantitativos. De hecho, trabajos como los de Barnes et al. (2014), Netter et al. (2011) y, Mulherin y Boone (2000) son algunos de los antecedentes académicos internacionales que se pueden encontrar en la literatura. Finalmente, este trabajo es un aporte a la literatura referida a las áreas del derecho económico y la organización industrial (antitrust).

En lo que sigue, el trabajo está organizado de la siguiente manera. La segunda sección es una breve introducción del control previo de F\&A en la Argentina. La tercera, describe el trabajo realizado por la CNDC junto con los criterios adoptados por los autores a la hora de clasificar las F\&A. La sección cuatro y cinco presentan los resultados obtenidos al analizar las operaciones resueltas por la CNDC. Por último, en la sexta sección se resumen las conclusiones del trabajo.

\section{Legislación nacional sobre fusiones y adquisiciones}

Desde finales de 1999, luego de la sanción de la Ley N²5.156 de Defensa de la Competencia (LDC), se estableció en Argentina el control previo7 de F\&A de empresas (operaciones de concentración económica según la terminología de la LDC). La nueva Ley $N^{\circ} 27.442$ sancionada el 9 de abril de 2018 también establece en el artículo 9 la obligación de notificación previa de las operaciones de concentración, pero incorpora como umbral una suma de unidades móviles cuyo valor se actualiza automáticamente utilizando la variación del índice de precios al consumidor (IPC) que publica el Instituto Nacional de Estadística y Censos (INDEC). La Comisión Nacional de Defensa de la Competencia publica en su página de internet los dictámenes y resoluciones referidos a las operaciones notificadas desde 1980 hasta la actualidad. El acceso público y gratuito a esta información es muy importante, tanto en términos de posibilitar el análisis de la

\footnotetext{
${ }^{4}$ La agencia de competencia del Reino Unido (CMA) publica estadísticas de los casos de concentración económica en su página oficial: Merger inquiry outcome statistics (Gov.uk, 7 de mayo 2014) https://assets.publishing.service.gov.uk/government/uploads/system/uploads/attachment_data/file/897788/ June_2020_-_merger_inquiry_outcome_statistics.csv/preview (consultada el 7 de julio 2020). La autoridad de competencia de la Comisión Europea también publica las estadísticas de F\&A desde 1990 hasta la actualidad: Statistics merger cases (European Commission) https://ec.europa.eu/competition/mergers/statistics.pdf (consultada el 7 de julio 2020).

5 Los últimos peer review realizados por la OECD fueron el de México (OECD, 2020), Brasil (OECD, 2019), Perú (OECD, 2018), Grecia (OECD, 2018) y Vietnam (OECD, 2018).

6 Los últimos peer review realizados por la UNCTAD fueron el de Botswana (UNCTAD, 2018), Argentina (UNCTAD, 2017) y Uruguay (UNCTAD, 2016).

7 En realidad, la obligación de notificación permite un plazo de una semana posterior al "cierre" de la operación (a partir de la fecha de la conclusión del acuerdo, de la publicación de la oferta de compra o de canje, o de la adquisición de una participación de control). Artículo 8 Ley N² 25.156 y Decreto 89/2001.
} 
jurisprudencia como para comparar criterios y enfoques adoptados bajo distintas administraciones.

El control previo de F\&A tiene carácter preventivo, busca evitar potenciales conductas anticompetitivas que pudieran producirse con una estructura de mercado más concentrada, y por ello no está exento de debate en cada caso en que se aplique.

En principio, no existe en el marco normativo una presunción de efectos adversos de las F\&A, de hecho, estas operaciones pueden generar sinergias que reduzcan los costos por debajo de los de las empresas individualmente consideradas y posteriores reducciones de precios, así como distintos tipos de mejoras de productividad y eficiencia o en términos de calidad y variedad de productos, inversión y desarrollo de nuevas tecnologías, entre otros. Sin embargo, la adopción del mecanismo de control previo de $F \& A$, de por sí implica que potencialmente un mayor nivel de concentración puede, ya sea conformar o fortalecer el poder de mercado de una firma y aumentar la probabilidad de que incurra en prácticas anticompetitivas unilaterales, o bien generar condiciones para la aparición de conductas coordinadas o colusivas.

El análisis de las decisiones de la CNDC en materia de F\&A da lugar a un interesante debate respecto de la aplicación de la política de competencia. Asimismo, la publicación de los dictámenes brinda información cuantitativa cuyo análisis permite obtener resultados y conclusiones independientes del enfoque normativo y las apreciaciones valorativas de la política pública en el marco del debate referido.

En este sentido, el objeto del presente trabajo es analizar el procedimiento de la CNDC y elaborar indicadores cuantitativos de desempeño, que permitan resumir los resultados del análisis de la evolución del número de casos evaluados por la CNDC, de los sectores económicos a los que pertenecen, de la naturaleza de cada operación (horizontales, verticales o de conglomerado), de las autorizaciones y condicionamientos de las operaciones notificadas y de la duración de los procedimientos y sus fases.

\section{Tipificación de F\&A y procedimientos para su evaluación}

\section{III.1. Criterios para la clasificación de F\&A}

A fin de poder construir indicadores de desempeño en materia de evaluación de $F \& A$, se utilizarán tres criterios para clasificar las operaciones: la naturaleza de la operación, el resultado de su evaluación por parte de la agencia de competencia y el sector económico en el que las partes desarrollan sus actividades.

La naturaleza de las operaciones refiere a las relaciones económicas entre las partes involucradas. Una operación tiene una naturaleza horizontal cuando las partes actúan como oferentes o demandantes de los mismos bienes o servicios, o de sus sustitutos cercanos y por lo tanto operan en un mismo mercado. Una operación implica una relación vertical cuando las partes se ubican en segmentos relacionados de la cadena 
productiva, es decir que una de las firmas involucrada en la operación tiene la potencialidad de ser cliente o proveedora de la otra (por ejemplo, una se dedica a la producción de un bien y otra a la distribución de ese mismo tipo de bienes) ${ }^{8}$. Los casos en los que no existen relaciones horizontales ni verticales, se denominan operaciones de conglomerado. ${ }^{9}$

Una operación puede también exhibir una naturaleza mixta, cuando se verifican simultáneamente relaciones horizontales y verticales (por ejemplo si las partes compiten en la distribución de un producto y a su vez una de ellas es fabricante del producto), también cuando hay relaciones horizontales y de conglomerado (por ejemplo cuando las partes son firmas multiproducto pero sólo en algunos de los productos hay relaciones horizontales), o verticales y de conglomerado (por ejemplo, si una firma que fabrica productos correspondientes a varios rubros adquiere a una distribuidora que sólo se dedica a uno de los rubros). En algunos casos pueden darse combinaciones de los tres tipos: horizontal, vertical y conglomerado.

Las operaciones de naturaleza horizontal son las que generan un impacto directo en la concentración de un mercado, ya que implican, a priori la fusión de dos competidores sea en una empresa o bien bajo control accionario común. Las operaciones de naturaleza vertical, al integrar en una misma firma (o grupo) distintos segmentos de la cadena productiva, puede afectar la competencia en cualquiera de los mercados verticalmente relacionados, sin embargo, no implica la fusión de competidores. Las concentraciones de conglomerado sólo podrían afectar la competencia potencial, en la medida de que alguna de las partes pudiera ser un entrante en el mercado de la otra.

Las operaciones de conglomerado son, evidentemente, las que menor preocupación generan en las autoridades de competencia. En cuanto a las otras operaciones, a priori, y considerando igual importancia relativa de las partes, las operaciones horizontales suelen generar mayor preocupación que las verticales ${ }^{10}$, pero los resultados en términos de las decisiones de las agencias de competencia dependen del

\footnotetext{
8 No es necesario que exista una relación comercial efectiva entre ambas empresas (es decir, no es necesario que una sea realmente cliente de la otra) para que se considere que ellas están verticalmente relacionadas. La relación comercial puede ser potencial en el sentido de que las actividades que desarrollan les permiten entablar una transacción proveedor-cliente. Por ejemplo, un fabricante del producto $A$ y de la marca $\mathrm{X}$ adquiere a un distribuidor del producto $\mathrm{A}$ de la marca $\mathrm{Y}$, el cual no tenía originalmente una relación contractual con el fabricante de $X$.

${ }^{9}$ Resolución SCDDC N¹64/2001

10 Por ejemplo, es más probable encontrar que los casos en los que se objete una operación vertical, cada una de las firmas involucradas presente una mayor participación de mercado que en los casos en los que se objete una operación cuando la cuota de mercado una concentración horizontal. En Europa, por caso, las directrices para la evaluación de operaciones no-horizontales dan una pauta de que resulta improbable que se objete una operación cuando la empresa resultante no supere el 30\% de participación en ninguno de los mercados afectados. En cambio, el parámetro para las operaciones horizontales es más bajo: es improbable que sea objetada una operación cuando la cuota de mercado posterior a la operación no supere el $25 \%$. Nótese que en el caso de una operación vertical, dos firmas con un $29 \%$ de cuota de mercado se encontrarían en el rango de poca probabilidad de objeción mientras que, en el caso de una operación horizontal, dos firmas con una participación de $13 \%$ se ubicarían fuera de dicho rango.

Véanse: "Directrices para la evaluación de las concentraciones no horizontales con arreglo al Reglamento del Consejo sobre el control de las concentraciones entre empresas" (2008/C 265/07), Diario Oficial de la Unión Europea, 18/10/2008; "Directrices sobre la evaluación de las concentraciones horizontales con arreglo al Reglamento del Consejo sobre el control de las concentraciones entre empresas" (2004/C 31/03), Diario Oficial de la Unión Europea, 5/2/2004.
} 
análisis de cada caso. Para evaluar cuantitativamente las relaciones entre la naturaleza de la operación y las decisiones de la agencia de competencia en Argentina, es necesario primero clasificar los distintos tipos de resultado posible.

Según la LDC vigente en Argentina, la evaluación de las operaciones de concentración económica para determinar sus efectos sobre el mercado y la competencia puede tener tres resultados: 1 . autorización (art.14 inc.a), 2. subordinación al cumplimiento de condiciones (art.14 inc.b) y 3 . denegación de la autorización (art.14 inc.c). En la práctica del control de F\&A en Argentina, se han dado algunas variantes adicionales que resulta de interés tener presente, a los efectos de construir indicadores cuantitativos que permitan a su vez obtener conclusiones cualitativas. En particular, la autoridad de competencia ha condicionado operaciones bajo distintas modalidades: en algunos casos ha autorizado la operación (art.14 inc.a) y en el mismo acto impuesto condiciones a las partes, mientras que en otros casos ha subordinado la operación al cumplimiento de condiciones (art.14 inc.b) para, una vez consideradas cumplidas las mismas, autorizar la operación (art.14 inc.a). En este sentido, el criterio empleado en este trabajo ha sido el de considerar condicionadas a todas las operaciones sujetas a algún tipo de restricción bajo cualquiera de las modalidades indicadas.

Asimismo, desde el punto de vista económico, es relevante tener en cuenta el tipo de condicionamiento realizado y en este aspecto se consideran tres categorías: los condicionamientos estructurales, los de conducta o comportamiento y los referidos a modificaciones en las cláusulas de no competencia (cláusula NC) de los contratos mediante los cuales se efectivizan las operaciones (Graf y Petrecolla, 2011).

Los condicionamientos estructurales consisten en desinversiones o ventas de marcas, filiales o unidades de negocios a terceros. Los condicionamientos de conducta o comportamiento son restricciones a las prácticas comerciales de las firmas, por ejemplo, que se comprometan a no realizar ventas atadas o a ofrecer acceso a sus instalaciones en condiciones no discriminatorias. En cuanto al último tipo de condicionamiento, el requerimiento de modificar la cláusula de no competencia es el de menor relevancia económica, ya que afecta a los propietarios o accionistas que dejan el mercado y no a las firmas que permanecen en él. ${ }^{11}$

\section{2. Procedimientos para el control de F\&A en Argentina}

En Argentina la LDC establece un plazo máximo de 45 días hábiles administrativos para decidir sobre el resultado de una solicitud de autorización para una operación de concentración económica. En los casos en los que la autoridad de defensa de la competencia considere que la operación notificada tiene la potencialidad de restringir o distorsionar la competencia, de modo que pueda resultar perjuicio para el interés económico general, previo a tomar una decisión comunicará a las partes sus objeciones mediante un informe fundado y las convocará a una audiencia especial para considerar posibles medidas que mitiguen el efecto negativo sobre la competencia. En

\footnotetext{
11 Las cláusulas de no competencia son restricciones que operan sobre los vendedores para que no vuelvan al mercado a competir con la empresa a la que le están vendiendo sus activos por un período de tiempo. En general, la CNDC objeta operaciones en las que dicho período es muy largo o cuando hace referencia a bienes o servicios que no fueron objeto de la operación.
} 
los casos mencionados, el plazo de resolución puede extenderse por hasta 120 días adicionales para la emisión de la resolución, mediante dictamen fundado. Dicho plazo podrá suspenderse hasta tanto las partes respondan a las objeciones presentadas por la CNDC. Transcurrido dicho plazo la operación queda autorizada en forma tácita. Sin embargo, el hecho de que el plazo se compute en días hábiles administrativos ha implicado una interpretación diversa respecto del momento en que debe comenzar a computarse el plazo y los momentos en los que debe suspenderse y reanudarse, lo cual ha generado que la duración del trámite resulte muy variable en distintos casos.

Con el objeto de analizar en mayor detalle la duración de los trámites y poder construir indicadores de desempeño apropiados, es necesario tener en cuenta las distintas fases establecidas en los procedimientos de evaluación de las operaciones de F\&A en Argentina.

Es importante notar que el caso argentino ha presentado una divergencia entre lo establecido en la LDC y la práctica, originada en que la Ley prevé la creación de un Tribunal de Defensa de la Competencia (TDC) como autoridad de aplicación, el cual no ha sido conformado aún. En tal contexto, y en lo que específicamente atañe al control de F\&A, la agencia de competencia (la CNDC) es la que realiza la mayor parte de las tareas y el procedimiento, pero emite un dictamen que no es vinculante. La decisión que tiene efectos jurídicos para las partes involucradas en una operación es la resolución de la Secretaría de la cual depende la CNDC. En el período analizado, la CNDC dependió de la Secretaría de Industria y Comercio, de la Secretaría de Defensa de la Competencia, de la Secretaría de Coordinación Técnica y, actualmente, de la Secretaría de Comercio Interior. Por lo tanto, la fase final de los trámites de F\&A han sido siempre la emisión del dictamen de la CNDC y, posteriormente, de la resolución de la Secretaría de Estado correspondiente ${ }^{12}$.

El trámite se inicia con la notificación y la presentación de información por parte de las empresas involucradas en una operación de concentración económica. A partir del año 2001 se agregó un límite inferior para las operaciones sujetas a notificación ${ }^{13}$. Este límite consistía en que las operaciones que no superen los AR $\$ 20$ millones no debían ser notificadas ${ }^{14}$, a pesar de que el volumen de negocios total del conjunto de las empresas afectadas superase en el país la suma de AR $\$ 200$ millones. Esta modificación implicó que dejen de notificarse operaciones pequeñas que anteriormente eran notificadas debido al volumen de negocios total de la empresa controlante o los grupos económicos involucrados. Como consecuencia se redujo significativamente la cantidad de notificaciones luego de 2001 (OECD, 2006). Como fue mencionado, la nueva Ley No 27.442 establece el valor de los umbrales en función de unidades móviles. En ese sentido, cuando la suma del volumen de negocio total del conjunto de empresas afectadas supere en el país la suma equivalente a 100 millones de unidades

\footnotetext{
12 Si bien cambiaban de denominación, las Secretarías mantenían las mismas funciones en materia de Defensa de la Competencia.

${ }^{13}$ Decreto N³96/2001.

${ }^{14}$ Salvo que en el plazo de 12 meses anteriores se hubieran efectuado operaciones que en conjunto superen los AR $\$ 20$ millones, o que en los últimos 36 meses superen los AR $\$ 60$ millones. Las operaciones sujetas a las acumulaciones de 12 y 36 meses deben haberse verificado en el mismo mercado.
} 
móviles, deberán ser notificados para su examen previamente. Asimismo, una concentración económica se encontrará exceptuada de notificación cuando el monto de la operación y el valor de los activos situados en la República Argentina objeto de la operación no superen, cada uno de ellos, respectivamente, la suma equivalente a 20 millones de unidades móviles.

Los requerimientos de información para las empresas involucradas y los procedimientos llevados a cabo por la CNDC se encuentran establecidos por la Resolución SDCC N40/2001. Estos procedimientos establecen la presentación de tres tipos de formularios, que a su vez se encuentran asociados a distintas fases de análisis de la operación y a diferentes subdivisiones del plazo total de 45 días establecido en la LDC, según se ilustra en la Figura 1. Como fue aclarado, tras la sanción de la Ley No 27.442 se establece que en los casos en que el Tribunal de Defensa de la Competencia considere que la operación notificada tiene la potencialidad de restringir o distorsionar la competencia el plazo de resolución del Tribunal de Defensa de la Competencia podrá extenderse por hasta 120 días adicionales para la emisión de la resolución.

Figura 1. Fases y plazos de los trámites de control de F\&A de la CNDC fijados en la normativa ${ }^{15}$

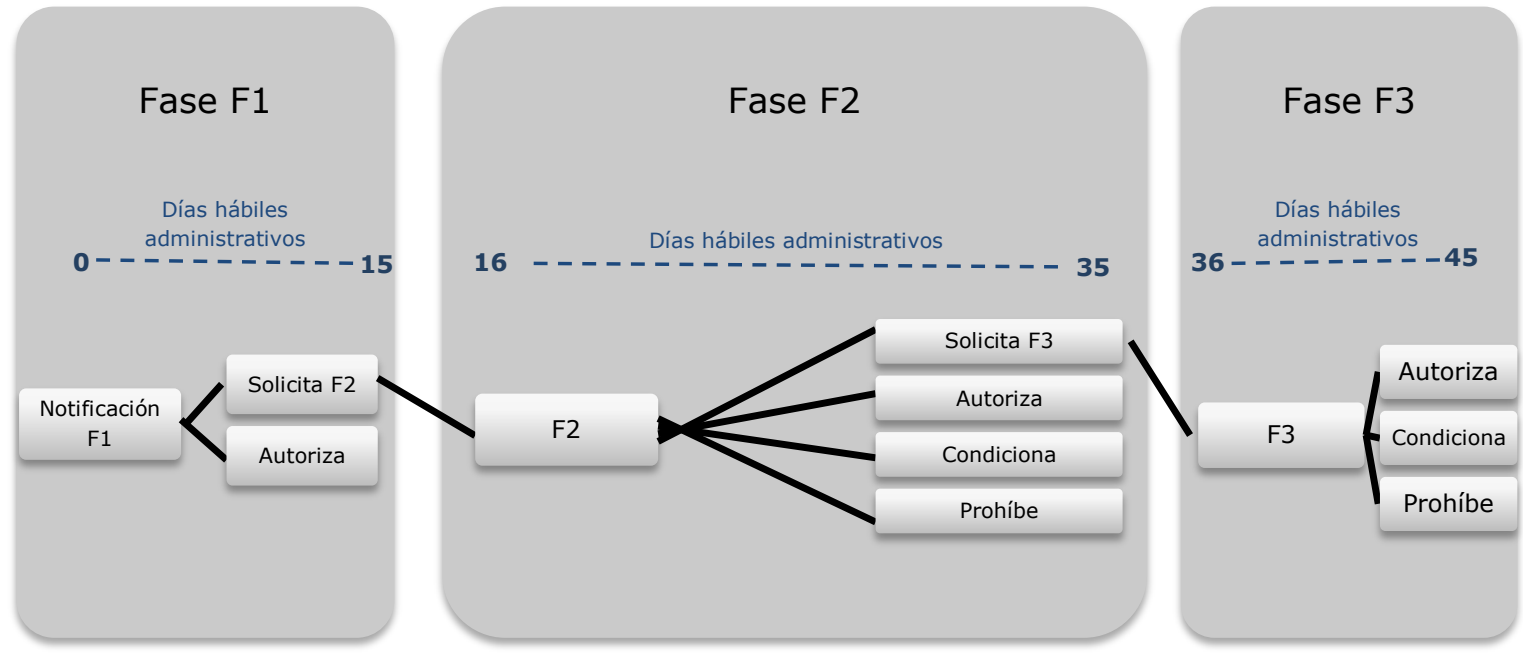

Fuente: Greco, Petrecolla, Romero, \& Romero Gómez, (2013).

El primero de los formularios es el $\mathrm{F} 1$, que es obligatorio para todos los casos y con el cual se inicia la notificación de la operación de concentración. Este formulario es estándar y contiene información sobre las empresas notificantes, las empresas involucradas y la concentración económica y sus antecedentes, el mercado geográfico relevante e información cuantitativa del mercado. Esta información se limita a determinar si la concentración afecta significativamente a la estructura del mercado. La CNDC dentro de los 15 días hábiles administrativos posteriores a la notificación debe resolver si autoriza la operación o si requiere la presentación de la información del formulario F2, ya que la información presentada en el F1 es insuficiente para la autorización.

\footnotetext{
15 Resolución SDCC N 40/2001.
} 
El formulario F2 tiene como propósito permitirle a la CNDC delimitar con más precisión el mercado relevante afectado por la operación y el grado de concentración de este, y profundizar el análisis de las características del proceso competitivo y el grado de desafiabilidad del mercado. Para este análisis se requiere a las empresas que presenten información cualitativa y cuantitativa sobre el mercado relevante del producto y geográfico, sobre el proceso productivo, sobre la existencia de productos diferenciados y sus características, sobre los costos de producción, la existencia de barreras a la entrada y las ganancias de eficiencia que se esperan como producto de la operación. El procedimiento otorga a la CNDC un plazo de 35 días hábiles administrativos posteriores a la notificación de la operación para autorizar, denegar o condicionar la operación, o para requerir la información del formulario F3.

El formulario F3 es la última instancia o fase de evaluación y está prevista sólo para aquellas operaciones de mayor complejidad o con mayor potencialidad de afectar la competencia. A diferencia de los formularios F1 y F2, no es estándar. La información requerida es confeccionada por la CNDC para que se ajuste a cada caso en particular. ${ }^{16}$ Entre 1999 y 2001 el procedimiento estuvo regido por la Resolución SICM No 726/1999, que establecía un formulario F1 más amplio (similar a la combinación de los formularios F1 y F2 actuales) y un formulario F2 no estándar (del tipo del formulario F3 actual). Adicionalmente, el procedimiento establecido mediante dicha norma no preveía subdivisiones del plazo de 45 días de la LDC.

Los plazos establecidos suelen ser interrumpidos en diferentes ocasiones, cuando la CNDC realiza observaciones por considerar incompletas las presentaciones o bien cuando solicita la presentación de los formularios F2 0 F3 ${ }^{17}$. En la práctica de implementación de los procedimientos se han observado diferencias respecto de las fases establecidas en la normativa e ilustradas en la Figura 1: por ejemplo, se han condicionado operaciones en las que el trámite sólo se desarrolló en la primera fase y no se solicitó el formulario F2. Asimismo, se han verificado variaciones significativas en la duración de los trámites, lo cual será analizado con detalle en la sección 4.

\section{Análisis de las operaciones de concentración}

\section{IV.1. Evolución de la cantidad de operaciones}

El análisis de la evolución de la cantidad de casos fue llevado a cabo considerando los dictámenes y resoluciones disponibles en el sitio de internet de la Comisión Nacional de Defensa de la Competencia. ${ }^{18}$ En total se analizaron 1.310 operaciones para el período comprendido entre los años 1999 y 2019.

\footnotetext{
16 La CNDC también puede pedir información adicional (no contenida en los formularios) si es que la considera necesaria para evaluar la concentración y convocar a los notificantes de la operación a una audiencia informativa. Ni la información general ni las audiencias interrumpen los plazos previstos para la evaluación.

17 El plazo no comienza a computarse hasta que la CNDC no considera completo el F1.

${ }^{18}$ http://www.cndc.gov.ar/consultas-dictamenes.htm
} 
Al analizar los datos de la Tabla 1 se puede ver que en el año 2001 la cantidad de dictámenes de operaciones de concentración económica se redujo de forma considerable, debido a la reforma llevada a cabo en marzo de ese año por la cual se elevaron los requisitos mínimos necesarios para que se deba notificar una operación. Posteriormente, entre los años 2002 y 2015 se registró un promedio de 39 operaciones por año, con la menor cantidad de casos en el año $2015^{19}$, y luego, en el período 2016 2019, un considerable incremento del promedio de operaciones por año, que se elevó a 124, con un máximo de 190 casos en el año 2017.

\section{IV.2. Naturaleza y resultado de las operaciones}

La mayor parte de las operaciones evaluadas por la CNDC en el período analizado fueron de naturaleza horizontal ( $\mathrm{H}$ en la Tabla 1), sumando 508 casos. Si se agregan las operaciones mixtas con alguna relación horizontal (horizontales-verticales: $\mathrm{H}-\mathrm{V}$, horizontales-conglomerado: $\mathrm{H}-\mathrm{C}$ y horizontales-verticales-conglomerado: $\mathrm{H}-\mathrm{V}-\mathrm{C}$ ), en total 251 casos, se llega a que el 57,9\% de las operaciones (759) presentó relaciones horizontales de algún tipo. Los conglomerados puros fueron 379 (28,9\% del total) y las operaciones verticales puras ascendieron a 168 (12,8\% del total). Si se consideran todas las operaciones con algún tipo de relación vertical, se llega a 414 casos (31,6\% del total).

Tabla 1: Naturaleza de las operaciones

\begin{tabular}{ccccccccc}
\hline Año & Casos & H & V & HV & C & VC & HC & HVC \\
\hline 1999 & 7 & 6 & 1 & & & & & \\
2000 & 161 & 87 & 16 & 20 & 38 & & & \\
2001 & 99 & 48 & 20 & 15 & 16 & & & \\
2002 & 25 & 9 & 9 & 4 & 3 & & & \\
2003 & 40 & 6 & 9 & 17 & 7 & & & \\
2004 & 43 & 14 & 5 & 13 & 11 & & \\
2005 & 43 & 11 & 4 & 20 & 8 & & \\
2006 & 61 & 18 & 4 & 25 & 14 & & & \\
2007 & 34 & 12 & 9 & 6 & 7 & & & \\
2008 & 38 & 10 & 5 & 7 & 14 & 2 & & \\
2009 & 46 & 14 & 9 & 11 & 10 & & 2 & \\
2010 & 43 & 17 & 4 & 10 & 11 & & 1 & \\
2011 & 40 & 22 & 2 & 8 & 5 & & 2 & 1 \\
2012 & 33 & 12 & 2 & 7 & 12 & & & \\
2013 & 41 & 8 & 9 & 7 & 14 & 1 & 2 & \\
2014 & 38 & 12 & 4 & 10 & 11 & 1 & & \\
2015 & 21 & 7 & 2 & 4 & 7 & & 1 & \\
2016 & 108 & 31 & 13 & 15 & 48 & & 1 & \\
2017 & 190 & 76 & 20 & 18 & 76 & & & \\
2018 & 147 & 71 & 14 & 14 & 48 & & & \\
2019 & 52 & 17 & 7 & 9 & 19 & & & \\
\hline Total & $\mathbf{1 . 3 1 0}$ & $\mathbf{5 0 8}$ & $\mathbf{1 6 8}$ & $\mathbf{2 4 0}$ & $\mathbf{3 7 9}$ & $\mathbf{4}$ & $\mathbf{9}$ & \\
\hline
\end{tabular}

Nota: Fecha de búsqueda marzo de 2020. $\mathrm{H}=$ horizontal, $\mathrm{V}=$ vertical, $\mathrm{H}-\mathrm{V}=$ horizontal y vertical, $\mathrm{C}=$ conglomerado, $\mathrm{V}-\mathrm{C}=$ =vertical y conglomerado, $\mathrm{H}-\mathrm{C}=$ horizontal $\mathrm{y}$ conglomerado, y H-V-C=horizontal, vertical y conglomerado.

Fuente: elaboración propia con datos de la CNDC

\footnotetext{
19 En el año 1999 hay muy pocos casos debido a que a recién a fines de ese año entró en vigencia el control de $F \& A$ en Argentina.
} 
El año con mayor proporción de operaciones con relaciones horizontales fue 2011 (82,5\% de los casos). El año 2003 fue el de mayor proporción de operaciones que implicaran relaciones verticales $(67,5 \%)$, aunque la mayor parte eran casos mixtos $\mathrm{H}$ V. Por el lado de las concentraciones de conglomerado, su crecimiento fue errático, alternándose años de crecimiento junto con años de retracción. El año 2016 fue el de mayor incremento interanual $(+585,7 \%)$. Durante los 20 años del período de análisis (1999-2019), el promedio de operaciones de conglomerado fue de 19 casos anuales, no obstante, en 15 de dichos 20 años, el valor evidenciado fue menor.

Las operaciones pueden tener diferentes resultados, como son la autorización sin o con condicionamientos, la subordinación y la denegación de autorización. En las primeras 6 columnas de la Tabla 2 se puede apreciar la evolución de la cantidad total de casos y su resultado para cada año del período 1999-2019. Además, dicha tabla incluye una clasificación del tipo de condicionamiento de las operaciones según sus efectos económicos, diferenciándolos en estructurales, de conducta o comportamiento y aquellos referidos a cláusulas de "No Competencia" (últimas 3 columnas de la Tabla 2).

Al analizar los resultados de las operaciones de F\&A, se distingue que la gran mayoría de los casos fueron operaciones autorizadas (1.217). No obstante, resulta interesante investigar la proporción de operaciones autorizadas y su evolución en el tiempo, para lo cual se calculó la tasa de autorización como el cociente entre los casos autorizados y el total de casos de cada año.

De igual modo, para reflejar la evolución en el tiempo de la proporción de casos en los cuales no hubo una autorización sin condiciones ni restricciones, se calculó un indicador al que se lo denominó "Tasa de Condicionamiento", la cual es el complemento de la tasa de autorización ${ }^{20}$. Dado que dicho indicador incluye el porcentaje de casos en los cuales se objetaron las cláusulas de No Competencia de los contratos de adquisición, y que tales condicionamientos son de menor importancia cualitativa, ya que actúan sobre quienes dejan el mercado, se construyó un indicador que excluye los condicionamientos por cláusula NC ("Tasa de Condicionamiento Neto").

${ }^{20}$ La suma de las tasas de autorización y de condicionamiento es siempre 1 (100\%). 
20 años de control de Fusiones y Adquisiciones en Argentina (1999-2019), pp. 1-36 Juliana Cardinale, Diego Petrecolla, Carlos Romero

Tabla 2: Operaciones evaluadas según su resultado y tipo de condicionamiento

\begin{tabular}{|c|c|c|c|c|c|c|c|c|}
\hline \multirow[b]{2}{*}{ Año } & \multirow[b]{2}{*}{ Casos } & \multirow[b]{2}{*}{$\begin{array}{c}\text { Autorizada } \\
\mathbf{s}\end{array}$} & \multirow{2}{*}{$\begin{array}{c}\text { Autorizadas con } \\
\text { Condicionamient } \\
0\end{array}$} & \multirow[b]{2}{*}{$\underset{\mathbf{s}}{\text { Subordinada }}$} & \multirow[b]{2}{*}{ Denegadas } & \multicolumn{3}{|c|}{ Tipo de Condicionamiento o Subordinación } \\
\hline & & & & & & Estructural & $\begin{array}{c}\text { Comportamient } \\
0\end{array}$ & $\begin{array}{c}\begin{array}{c}\text { Cláusulas de } \\
\text { No }\end{array} \\
\text { Competencia } \\
\end{array}$ \\
\hline 1999 & 7 & 6 & 1 & & & & 1 & \\
\hline 2000 & 161 & 147 & 9 & 5 & & 2 & 8 & 4 \\
\hline 2001 & 99 & 93 & 2 & 3 & 1 & 2 & 3 & \\
\hline 2002 & 25 & 23 & & 1 & 1 & 1 & & \\
\hline 2003 & 40 & 34 & 2 & 3 & 1 & 2 & 1 & 2 \\
\hline 2004 & 43 & 38 & 1 & 4 & & 2 & 2 & 1 \\
\hline 2005 & 43 & 38 & 2 & 3 & & 1 & 2 & 2 \\
\hline 2006 & 61 & 58 & 1 & 2 & & 1 & 1 & 1 \\
\hline 2007 & 34 & 32 & 1 & & 1 & & 1 & \\
\hline 2008 & 38 & 34 & 2 & 2 & & 1 & 1 & 2 \\
\hline 2009 & 46 & 41 & 2 & 3 & & 3 & 2 & \\
\hline 2010 & 43 & 35 & & 8 & & 1 & 3 & 4 \\
\hline 2011 & 40 & 31 & 1 & 8 & & 1 & 3 & 5 \\
\hline 2012 & 33 & 28 & & 5 & & 1 & & 4 \\
\hline 2013 & 41 & 35 & & 6 & & 1 & 1 & 4 \\
\hline 2014 & 38 & 33 & 2 & 3 & & 1 & 4 & \\
\hline 2015 & 21 & 17 & & 4 & & & 2 & 2 \\
\hline 2016 & 108 & 108 & & & & & & \\
\hline 2017 & 190 & 189 & & 1 & & & & 1 \\
\hline 2018 & 147 & 145 & 1 & 1 & & 1 & 1 & \\
\hline 2019 & 52 & 52 & & & & & & \\
\hline Total & 1.310 & 1.217 & 27 & 62 & 4 & 21 & 36 & 32 \\
\hline
\end{tabular}

Fuente: elaboración propia con datos de la CND. 
En la Figura 1 se advierte que la Tasa de Condicionamiento varía durante el período analizado de forma cíclica, mostrando períodos de ascenso y de descenso. A partir del año 2008 comienza un período ascendente que se mantiene hasta el año 2011, año en que la Tasa de Condicionamiento alcanza el máximo valor (23\%) del período estudiado. Luego cae hasta el año 2014 (13\%), con un nuevo pico en 2015 y una importante caída al año siguiente, manteniéndose en niveles muy bajos hasta el final del período. Sin embargo, si se analiza la Tasa de Condicionamiento Neto, se puede ver que el tramo ascendente no es tan pronunciado. La Tasa de Condicionamiento Neto se ubica durante todo el período 2000-2015 en el rango entre el $5 \%$ y el 10\% (con las excepciones de 2006 con un 3\%, 2009 con un 11\%, 2012 con un 3\%, 2013 con 5\% y 2014 con 13\%). Estos valores resultan coincidentes con la experiencia internacional, que en la mayoría de los países exhibe una proporción que oscila entre el $5 \%$ y $10 \%$ de las fusiones notificadas sujetas a algún tipo de acción correctiva ${ }^{21}$. Al igual que la Tasa de Condicionamiento, entre 2016 y 2019 la Tasa de Condicionamiento Neto exhibe valores considerablemente bajos.

En lo formal, los condicionamientos de las operaciones han adoptado modalidades diversas para su instrumentación: en ciertos casos el dictamen y la resolución establecen los requisitos a cumplir por las partes (generalmente son los casos de subordinación de la autorización en los términos del artículo 14 inciso b de la LDC), para luego, una vez considerados cumplidos autorizar la operación; mientras que en otros casos se aceptan compromisos de las partes en los que explicitan las condiciones a cumplir (normalmente en estos casos la operación se autoriza en los términos del artículo 14 inciso a de la LDC, aunque simultáneamente se aprueba el compromiso que condiciona a las partes).

Un análisis más detallado de los casos con condicionamientos o en los que se denegó la autorización (en total fueron 93) ${ }^{22}$, permite desagregar las modalidades formales de los mismos de acuerdo con los tipos de condicionamiento considerando los efectos económicos que los mismos generan (estructurales, de comportamiento o vinculados a cláusula NC). En los datos exhibidos en la Tabla 3, se distingue que, entre las operaciones autorizadas con condicionamientos, predominan las condiciones de comportamiento (representan un $81,5 \%$ de las operaciones de este rubro). En las subordinaciones prevalecen los condicionamientos por no competencia (que representan el $50 \%$ ), aunque, si se consideran sólo los condicionamientos que afectan a quienes quedan en el mercado luego de la operación, la mayor parte son estructurales $(27,4 \%$ del total de operaciones subordinadas, y $54,8 \%$ si se excluyen los casos condicionados por cláusula NC).

\footnotetext{
${ }^{21}$ Véanse: OECD (2010), OECD y Banco Interamericano de Desarrollo (2006).

${ }^{22}$ Véanse la cuarta, quinta y sexta columnas de la Tabla 2.
} 
Figura 1: Evolución de la Tasa de Condicionamiento

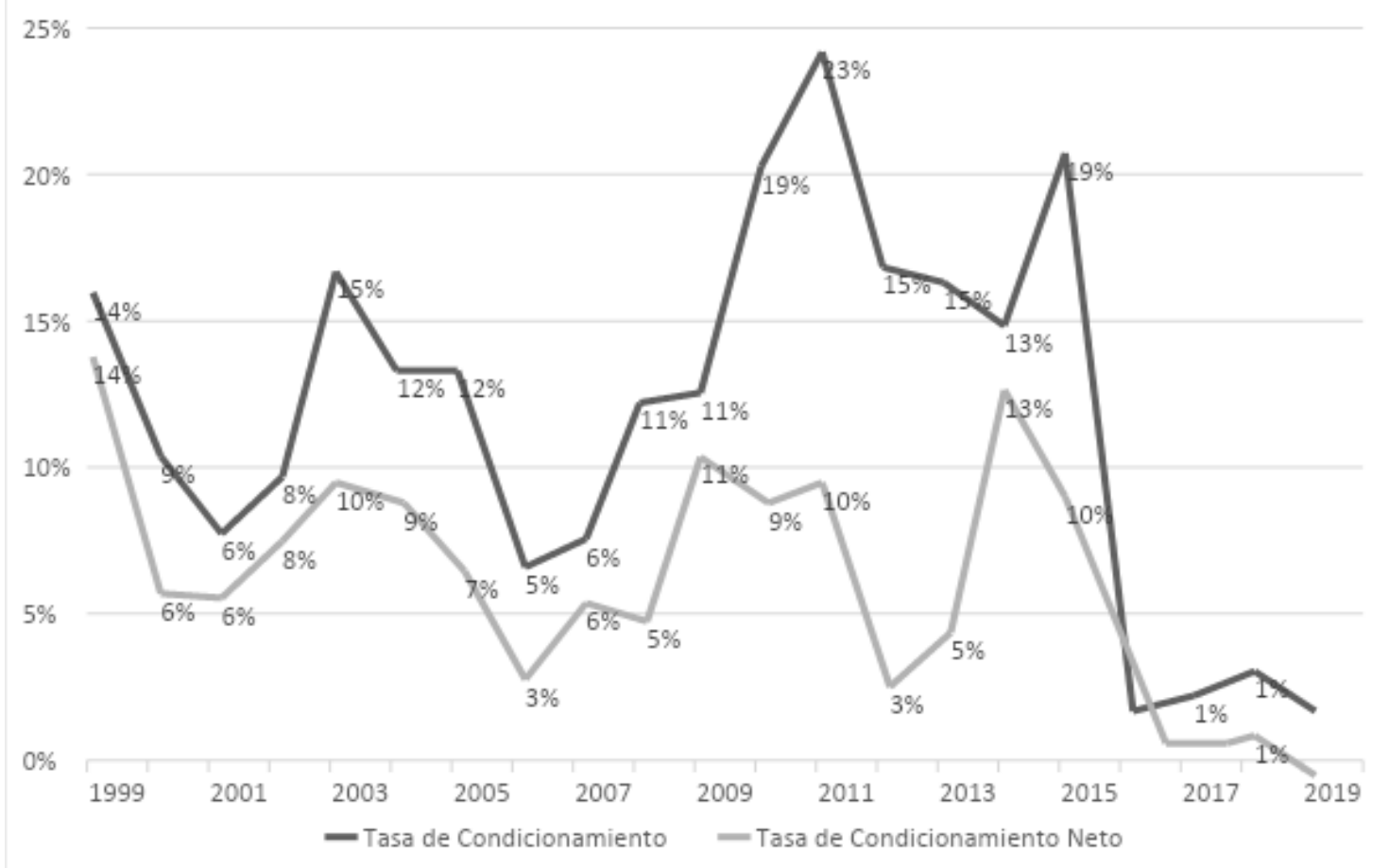

Fuente: elaboración propia con datos de la CNDC

Tabla 3: Operaciones condicionadas y denegadas según tipo de condicionamiento.

\begin{tabular}{|c|c|c|c|c|}
\hline Tipo de Condicionamiento & $\begin{array}{l}\text { Autorizadas con } \\
\text { Condicionamiento }\end{array}$ & $\begin{array}{l}\text { Subordinada } \\
\mathbf{s}\end{array}$ & Denegadas & $\begin{array}{c}\text { Total } \\
\text { Condicionada } \\
s+ \\
\text { Denegadas }\end{array}$ \\
\hline $\begin{array}{l}\text { Condicionamiento } \\
\text { Estructural }\end{array}$ & $14,8 \%$ & $27,4 \%$ & $100,0 \%$ & $26,9 \%$ \\
\hline . Desinversión & $14,8 \%$ & $27,4 \%$ & & $22,6 \%$ \\
\hline $\begin{array}{l}\text {. Denegación de } \\
\text { autorización }\end{array}$ & & & $100,0 \%$ & $4,3 \%$ \\
\hline $\begin{array}{l}\text { Condicionamiento por } \\
\text { Comportamiento }\end{array}$ & $81,5 \%$ & $22,6 \%$ & & $38,7 \%$ \\
\hline Cláusula de No Competencia & $3,7 \%$ & $50,0 \%$ & & $34,4 \%$ \\
\hline Total Rubro & $100,0 \%$ & $100,0 \%$ & $100,0 \%$ & $100,0 \%$ \\
\hline
\end{tabular}

Fuente: elaboración propia con datos de la CNDC

La Tabla 3 también muestra la distribución proporcional de los casos tomando en consideración el total de operaciones con algún tipo de restricción (operaciones condicionadas 0 subordinadas y autorizaciones denegadas) ${ }^{23}$. Los condicionamientos por comportamiento fueron los más numerosos en el período $(38,7 \%)$, seguidos por los de no competencia con un $34,4 \%$, algo que indica que aproximadamente un tercio de los condicionamientos no son muy relevantes en cuanto a su efecto económico. Los condicionamientos estructurales ${ }^{24}$, que son el tipo de condicionamiento más fuerte, fueron la porción menor (26,9\%). La participación de los condicionamientos estructurales puede subdividirse entre desinversiones $(22,6 \%)$ y operaciones rechazadas $(4,3 \%)$.

\footnotetext{
${ }^{23}$ Véase la última columna de la Tabla 2.

${ }^{24}$ Incluidos los casos cuya autorización fue denegada.
} 
La evolución en el tiempo de las proporciones de cada tipo de condicionamiento (surge de los datos de la Tabla 2) no muestra un patrón de comportamiento definido: en 2002, 2009 y 2018 los condicionamientos estructurales representaron el 50\% o más del total de casos con restricciones; en 2000, 2001, 2007, 2014 y 2015 la mitad o más de los condicionamientos fueron de conducta; y en siete de los últimos doce años (se exceptúan los años 2009, 2014, 2016, 2018 y 2019) prevalecieron los condicionamientos por cláusula NC con una proporción del $50 \%$ o superior; mientras que en los años 2003, 2004, 2005 y 2006 ningún tipo de condicionamiento superó el $40 \%$ del total.

Otra forma de profundizar el análisis cuantitativo y cualitativo de F\&A es el entrecruzamiento de categorías, de modo de evaluar los resultados de la evaluación realizada por la autoridad de competencia, incluido el tipo de condicionamiento, según su naturaleza. En la clasificación por naturaleza, las operaciones horizontales incluyen a las $\mathrm{H}, \mathrm{H}-\mathrm{C}$ y $\mathrm{H}-\mathrm{V}-\mathrm{C}$ y las verticales, a las $\mathrm{V}$ y $\mathrm{V}-\mathrm{C}$. Se hace este reagrupamiento ya que las operaciones mixtas, a excepción de las operaciones $\mathrm{H}-\mathrm{V}$, que se mantienen como una categoría separada, no son significativas, dada la baja cantidad de operaciones de esa naturaleza. El análisis de entrecruzamiento se exhibe en la Tabla 4.

Tabla 4: Resultado de la evaluación de las operaciones según su naturaleza.

\begin{tabular}{|c|c|c|c|c|c|c|}
\hline \multirow{3}{*}{$\begin{array}{c}\text { Naturaleza de la } \\
\text { operación }\end{array}$} & \multirow{3}{*}{$\begin{array}{l}\text { Autorizad } \\
\text { as }\end{array}$} & \multicolumn{4}{|c|}{ Condicionadas o Denegadas } & \multirow{3}{*}{ Total } \\
\hline & & \multicolumn{2}{|c|}{ Estructural } & \multirow{2}{*}{$\begin{array}{c}\text { Comportamient } \\
0\end{array}$} & \multirow{2}{*}{$\begin{array}{c}\text { No } \\
\text { Competencia }\end{array}$} & \\
\hline & & Denegadas & Desinversión & & & \\
\hline Horizontal & 477 & 1 & 13 & 14 & 14 & 519 \\
\hline Vertical & 161 & 1 & 1 & 6 & 3 & 172 \\
\hline $\begin{array}{c}\text { Horizontal } \\
\text { Vertical }\end{array}$ & 210 & 2 & 7 & 14 & 7 & 240 \\
\hline Conglomerado & 369 & 0 & 0 & 2 & 8 & 379 \\
\hline Total & 1.217 & 4 & 21 & 36 & 32 & $\begin{array}{c}1.31 \\
0\end{array}$ \\
\hline
\end{tabular}

Nota: Horizontal incluye $\mathrm{H}-\mathrm{C}$ y $\mathrm{H}-\mathrm{V}-\mathrm{C}$, mientras que Vertical incluye $\mathrm{V}-\mathrm{C}$

Fuente: elaboración propia con datos de la CNDC

En primer lugar, puede observarse que las operaciones sujetas a condiciones o denegadas son principalmente horizontales y/o verticales (83 de 93). Si bien se verificaron 10 casos de concentraciones de conglomerado que fueron subordinadas, a pesar de que este tipo de operaciones no suelen ser perjudiciales para la competencia, en 8 de esos casos el condicionamiento se refirió a la modificación de cláusula $\mathrm{NC}^{25}$.

Otro rasgo que surge del análisis y es consistente con lo que se podría esperar es que la tasa de autorización de las operaciones de conglomerado es la más alta, $97 \%$, mientras que en el caso de las horizontales y verticales es de $92 \%$ y $94 \%$ respectivamente, y aún menor en el de las operaciones mixtas horizontalesverticales $(88 \%)$.

Asimismo, de los 93 casos condicionados o denegados, 61 corresponden a aquellos en los que el condicionamiento no se originó en cláusula NC. De estos 61, 28

25 Una cuestión que podría debatirse, aunque excede el alcance del presente trabajo, es la referida a los fundamentos para subordinar la autorización de operaciones de conglomerado, que en ningún caso afectan la concentración de los mercados relevantes en forma directa y en la gran mayoría de los casos no afectan la competencia, a que modifiquen la cláusula de No Competencia. 
correspondieron a operaciones horizontales, 23 a operaciones mixtas (horizontalvertical), 8 a verticales y 2 a conglomerado.

La Figura 2 focaliza en dichos casos con condicionamientos (excluidos los referidos a cláusula NC) y en las operaciones a las que se les denegó la autorización, a fin de estudiar las diferencias según la naturaleza de las operaciones.

Figura 2: Tipo de condicionamiento según la naturaleza de las operaciones. (Excluyendo condicionamientos por cláusulas de No Competencia).

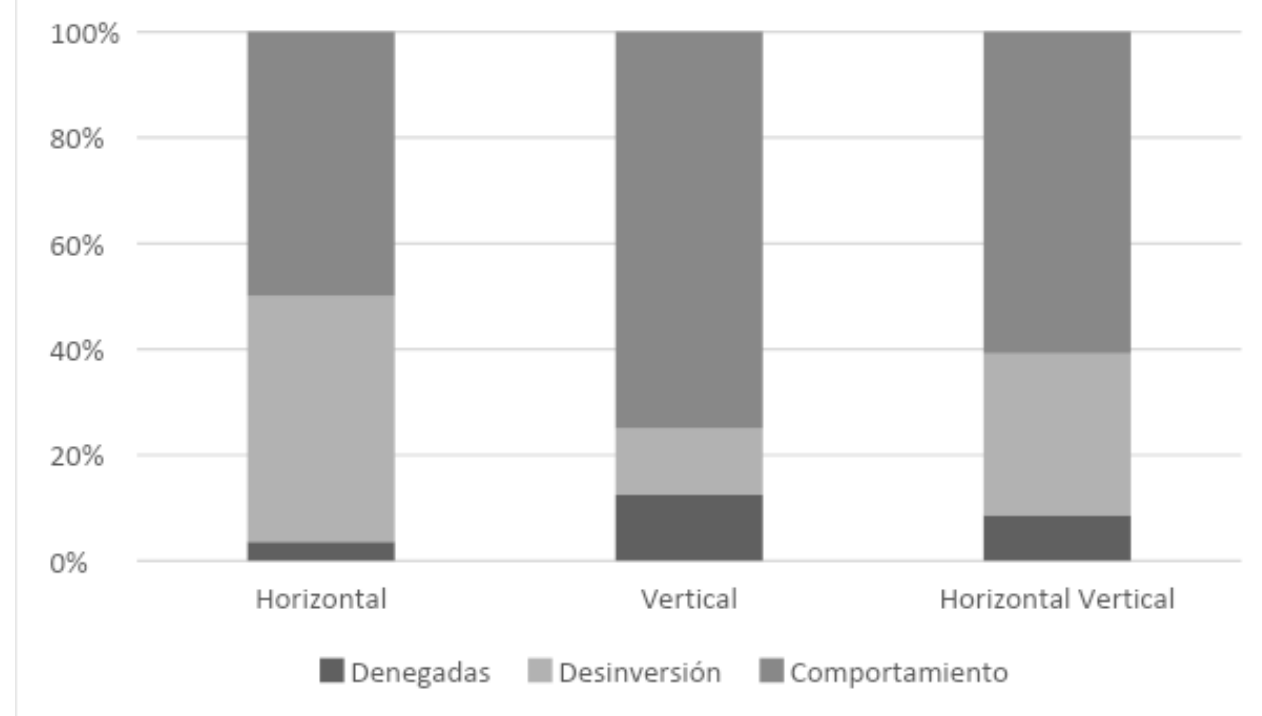

Nota: Horizontal incluye $\mathrm{H}-\mathrm{C}$ y $\mathrm{H}-\mathrm{V}-\mathrm{C}$, mientras que Vertical incluye $\mathrm{V}-\mathrm{C}$ Fuente: elaboración propia con datos de la CNDC

De este análisis surgen resultados coherentes con los efectos que podrían esperarse según la naturaleza de las operaciones, de acuerdo con lo expuesto en la sección 2.1. En primer lugar, las operaciones horizontales fueron las que mostraron una mayor proporción de condicionamientos estructurales (desinversiones y autorizaciones denegadas), los cuales representaron el $50 \%$ de los casos horizontales condicionados ( $46 \%$ fueron desinversiones y $4 \%$ rechazos de la operación). En el caso de las operaciones verticales, el $75 \%$ de los condicionamientos fueron de comportamiento. Las operaciones mixtas (horizontalvertical) condicionadas representan un caso intermedio en cuanto a su desagregación, el $61 \%$ de los condicionamientos fueron de comportamiento y el $39 \%$ estructurales (30\% desinversiones y $9 \%$ rechazos).

\section{IV.3. Análisis sectorial de las operaciones}

En esta subsección se presentan los resultados del análisis de las operaciones de F\&A desagregadas por sectores económicos. Las operaciones fueron clasificadas en diferentes categorías para buscar regularidades y diferencias en las decisiones de la CNDC en materia de autorizaciones y condicionamientos.

En la Tabla 5 (primera columna) se enumeran los sectores considerados en la clasificación. La metodología para definir la clasificación tomó como punto de partida las categorías utilizadas en las Memorias de la CNDC, para luego desagregar aquellas categorías más heterogéneas y que aglutinaban una cantidad relativamente elevada de casos. 
La Tabla 5 presenta la cantidad de operaciones desagregadas por sector y según el resultado de la evaluación realizada por la autoridad de competencia. Resulta de particular interés la cantidad de condicionamientos o denegaciones de autorización (en particular cuando se excluyen los que se originan en cláusula NC), cuyo análisis permite indicar que la mayor Tasa de Condicionamiento Neto $(18 \%)$ correspondió al sector de "Telecomunicaciones, Medios y Publicidad", en el cual se destacan varios condicionamientos de conducta en operaciones en el mercado de TV por cable. Otros sectores con una Tasa de Condicionamiento Neto superior a la media fueron los de "Productos Químicos", "Alimentos y Bebidas" (con mayoría de condicionamientos en la producción y distribución de bebidas), "Papel, Plásticos y Vidrio" y "Construcción e Inmobiliario".

En el otro extremo, entre los sectores con baja Tasa de Condicionamiento Neto (menor al 2\%) se encuentran: "Agricultura, Ganadería, y Pesca", con el menor valor; "Metalmecánico"; "Comercialización Minorista y Mayorista" y "Energía y Combustibles Líquidos". Cabe destacar que, en este último sector, en el cual se destacan varios casos de empresas reguladas ${ }^{26}$, si bien la Tasa de Condicionamiento Neto es del $2 \%$, se evaluaron muchos casos de adquisiciones de estaciones de servicio de poca envergadura. Además, dado que es el sector con la mayor cantidad de operaciones (269), los casos condicionados afectan en menor medida a la Tasa de Condicionamiento Neto. En el sector de "Energía y Combustibles Líquidos" solo hubo una operación condicionada en la generación de electricidad ${ }^{27}$, siendo los demás condicionamientos en los combustibles líquidos. Por su parte, en los sectores "Agricultura, Ganadería, y Pesca", "Metalmecánico", y "Comercialización Minorista y Mayorista", se registró una operación condicionada en cada uno, siendo un condicionamiento de tipo estructural en el primer sector, y por conducta

dos.

\footnotetext{
${ }^{26}$ Algunos aspectos de las políticas de competencia en sectores regulados pueden verse en Petrecolla y Ruzzier, (2004).

${ }^{27}$ Véase: Petrecolla y Romero (2010)
} 
Tabla 5: Análisis sectorial de resultados de las evaluaciones de F\&A.

\begin{tabular}{|c|c|c|c|c|c|c|c|}
\hline \multirow[b]{2}{*}{ Sector } & \multirow[b]{2}{*}{ Autorizadas } & \multicolumn{3}{|c|}{ Condicionamientos } & \multirow[b]{2}{*}{$\begin{array}{c}\text { Denegada } \\
\mathbf{s}\end{array}$} & \multirow[b]{2}{*}{ Total } & \multirow{2}{*}{$\begin{array}{l}\text { Tasa } \\
\text { de } \\
\text { Cond. } \\
\text { Neto }\end{array}$} \\
\hline & & $\begin{array}{c}\text { Estructura } \\
\text { I }\end{array}$ & Conducta & $\begin{array}{c}\text { Cláusula de } \\
\text { No } \\
\text { Competencia }\end{array}$ & & & \\
\hline Agricultura, Ganadería y Pesca & 82 & 1 & & 3 & & 86 & $1 \%$ \\
\hline Alimentos y Bebidas & 109 & 6 & 4 & 5 & & 124 & $8 \%$ \\
\hline $\begin{array}{l}\text { Comercialización Minorista y } \\
\text { Mayorista }\end{array}$ & 61 & & 1 & & & 62 & $2 \%$ \\
\hline Construcción e Inmobiliario & 33 & 1 & 1 & 2 & & 37 & $5 \%$ \\
\hline Energía y Combustibles líquidos & 269 & 3 & 1 & & 1 & 274 & $2 \%$ \\
\hline Servicios Financieros y Seguros & 115 & 1 & 2 & 5 & & 123 & $2 \%$ \\
\hline Medicamentos y Salud & 75 & 2 & 1 & 4 & & 82 & $4 \%$ \\
\hline Metalmecánico & 61 & & 1 & 1 & & 63 & $2 \%$ \\
\hline Papel, Plásticos y Vidrios & 24 & 1 & 1 & 4 & & 30 & $7 \%$ \\
\hline Productos Químicos & 42 & 2 & 2 & 1 & & 47 & $9 \%$ \\
\hline $\begin{array}{l}\text { Telecomunicaciones, Medios de } \\
\text { Comunicación y Publicidad }\end{array}$ & 93 & 3 & 15 & 1 & 2 & 114 & $18 \%$ \\
\hline $\begin{array}{l}\text { Transporte, Almacenamiento y } \\
\text { Logística }\end{array}$ & 46 & & 1 & & 1 & 48 & $4 \%$ \\
\hline Otros & 207 & 1 & 6 & 6 & & 220 & $3 \%$ \\
\hline Total & 1.217 & 21 & 36 & 32 & 4 & 1.310 & $5 \%$ \\
\hline
\end{tabular}

21

36

32

1.310

$5 \%$

Notas: "Medicamentos y Salud" incluye las operaciones que involucran a empresas de salud prepagas y diferentes servicios de salud (como servicios de diálisis). El sector Agropecuario, no solo incluye la producción agrícola y ganadera, sino que también abarca productos complementarios como fertilizantes y semillas. El sector Metalmecánico incluye a la siderurgia, fabricación y comercialización de automóviles y tractores, y el mercado de autopartes. En "Transporte y Logística" se abarcan los transportes de mercaderías y pasajeros, como también las operaciones que involucren redes viales, y además se incluyen los casos relacionados con el servicio postal. El sector "Construcción e Inmobiliario" comprende a los materiales para la construcción (como por ejemplo el cemento) y también a la actividad inmobiliaria (como la locación de espacios comerciales). "Comercialización Minorista y Mayorista" incluye a los supermercados (minoristas o mayoristas) y a comercios que vendan directamente al consumidor. "Servicios Financieros y Seguros" abarca a las concentraciones que involucren a entidades financieras y a empresas en el mercado de seguros. "Energía y Combustibles líquidos" incluye a las operaciones de combustibles líquidos, electricidad e hidrocarburos.

Fuente: elaboración propia con datos de la CNDC 


\section{Análisis de duración}

\section{V.1. Metodología}

La normativa vigente en Argentina establece plazos para los trámites utilizando como unidad de medida los días hábiles administrativos. Sin embargo, esa unidad de medida no resulta útil para comparar diferentes casos o para evaluar la evolución en el tiempo de la duración de los trámites, dada la heterogeneidad en los cómputos de los plazos de cada operación. Es por ello que se utilizó como unidad de medida la cantidad total de días transcurridos entre el inicio y la finalización del trámite y cada una de sus fases (días corridos).

La duración total de los trámites de evaluación de F\&A se computa entre el día de notificación de la operación y el de emisión de la resolución que la autoriza, condiciona o le deniega autorización. Las fases de evaluación que se consideraron a los fines de desagregar la duración de los trámites son las siguientes:

- Formularios: tiempo insumido en completarlos, desagregándose de corresponder, F1, F2 y F3.

- Dictamen: lapso desde que se completan los formularios hasta que la CNDC emite el dictamen.

- Resolución: período entre la emisión del dictamen y de la resolución.

Cada fase de evaluación se inicia en la fecha de finalización de la fase anterior. La duración de la fase de los formularios se da por concluida cuando la CNDC los da por aprobados $^{28}$. El dictamen y resolución, en su respectiva fecha de emisión, determinan la finalización de dichas fases.

A los fines expositivos y de análisis, se ha calculado la duración promedio de los trámites de F\&A resueltos en cada año ${ }^{29} 30$.

\section{V.2. Análisis de la duración de los trámites de F\&A}

La duración promedio de los trámites de evaluación de F\&A en Argentina entre 1999 y 2019 fue de 478 días (cerca de 16 meses o un año y cuatro meses), según se exhibe en la Tabla 6. Sin embargo, si se analiza la evolución intertemporal de la duración de los trámites, se observa un período de creciente duración de los trámites hasta el año 2016, seguido de una reversión de esta tendencia y reducción de la duración promedio en los años siguientes. La duración promedio de los trámites pasó de 103 días en el

\footnotetext{
${ }^{28}$ En los casos en los cuales las partes presentan en forma simultánea los formularios F1 y F2, se considera la fecha final de aprobación de cada formulario para computar su duración específica, pero la duración de toda la fase de formularios no va a ser la suma de la duración del F1 y F2, sino el lapso que transcurra hasta la aprobación del último de ambos formularios en ser aprobado (generalmente el F2).

${ }^{29}$ En varios casos los trámites han durado más de un año, y por lo tanto las operaciones no se registran en el año de su notificación sino en el de emisión de la resolución.

30 Se excluyen del análisis los casos en los que no se encontraban disponibles las resoluciones o parte de la información relevante estaba incompleta.
} 
año 2000 a 1.113 días en 2016, lo que implica un incremento de $878 \%{ }^{31}$, cayendo posteriormente hasta los 472 en el año 2019 (58\% menos que el máximo alcanzado en 2016).

Como se indicó previamente, los valores de la duración promedio se expresan en días corridos. Se puede construir un indicador que muestre la relación entre los días hábiles administrativos y los días corridos siendo el mismo igual al cociente entre la duración promedio total en días corridos y $45^{32}$. Este indicador señala que en el año 2000 un día hábil administrativo equivalía a 2,3 días corridos (es decir que el plazo de 45 días hábiles administrativos representó 103 días corridos en promedio). En 2016 se llegó a un máximo de 24,7 días corridos por cada día hábil administrativo. A partir de dicho año el indicador descendió hasta ubicarse en un valor de 10,5 días corridos por cada día hábil administrativo para el año 2019. El promedio para el período 2000-2006 fue de 2,9 días, mientras que para los años comprendidos entre 2007-2016 y 2017-2019 el promedio fue de 13,8 días corridos por cada día hábil administrativo.

El mayor incremento interanual en la duración promedio de los trámites se verificó en 2009: el aumento en la duración fue del $60 \%$ (o 165 días). Sin embargo, un análisis de largo plazo permite identificar, por un lado, un cambio en la tendencia de crecimiento de la duración en 2006 y luego otro, en 2016. En la Figura 3 se presenta la duración promedio anual de los trámites de F\&A subdividida en tres períodos: 2000-2006, 20072016 y $2017-2019$.

Figura 3: Duración de los trámites de evaluación de F\&A

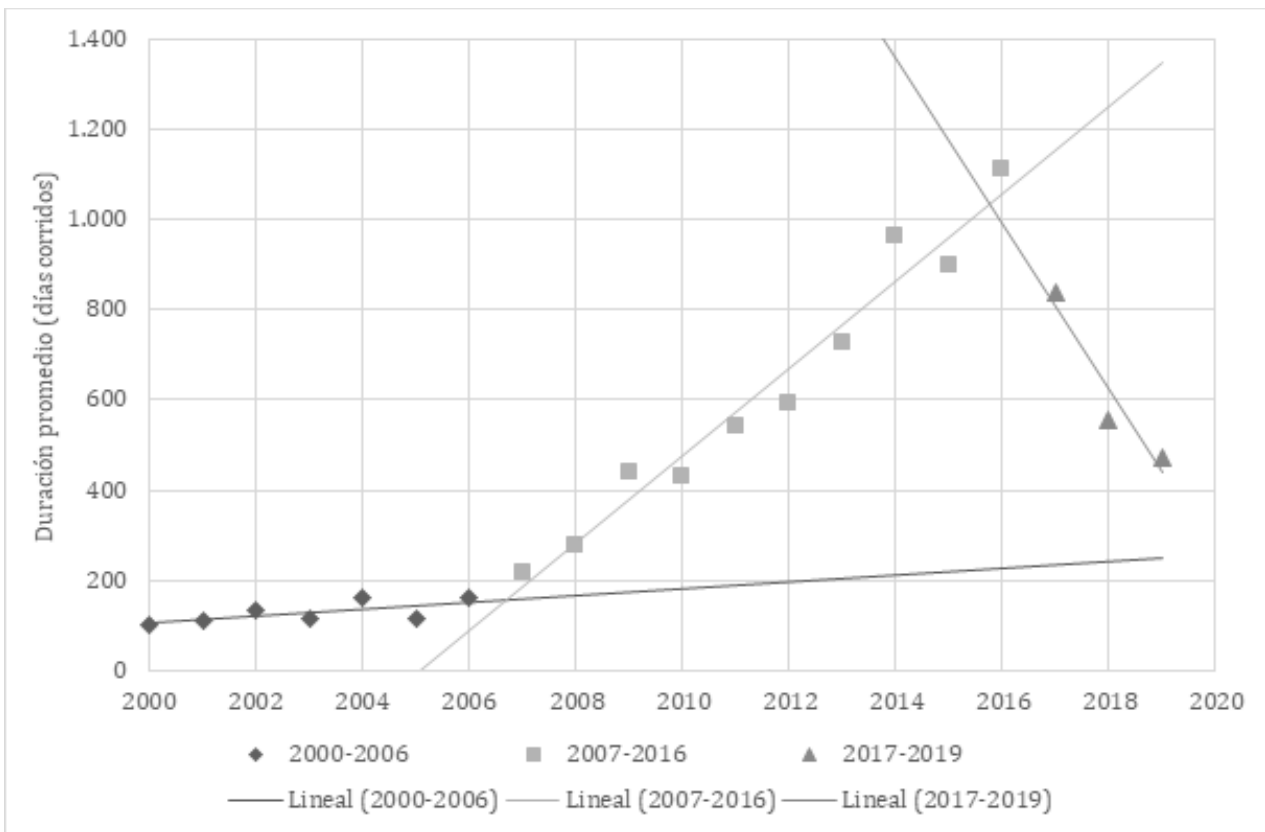

Fuente: elaboración propia con datos de la CNDC

\footnotetext{
${ }^{31}$ La cantidad de casos de 1999 fue muy baja, por lo cual la duración promedio de los trámites finalizados en ese año no se considera representativa y no se incluye en las comparaciones interanuales.

${ }^{32}$ Calculado como el cociente entre la duración promedio total en días corridos y 45, que es la cantidad de días hábiles administrativos máximos para el análisis de una operación.
} 
En el período 2000-2006 la tendencia fue levemente creciente y errática, con aumentos y disminuciones de la duración promedio en diferentes años ${ }^{33}$. La duración promedio de los trámites osciló entre 103 y 161; claramente por debajo de la duración promedio de los años posteriores.

A partir de 2006, y hasta 2016, puede notarse una tendencia fuertemente creciente, con una tasa de crecimiento significativamente mayor que en el lapso anterior. ${ }^{34}$ La duración promedio alcanzó su máximo en el año 2016 (1.113 días), el cual también fue el máximo absoluto.

Entre los años 2017-2019, se revirtió la tendencia creciente ${ }^{35}$. El máximo del período fue en el año 2017 (839 días) y a partir de ahí se evidenció una clara disminución de la duración promedio de los trámites hasta alcanzar el valor de 472 en 2019.

En términos comparados, la duración promedio en otras jurisdicciones deja en evidencia el pobre desempeño de la agencia de competencia argentina. Por ejemplo, en Chile la duración promedio de las investigaciones de concentración llevadas a cabo por la Fiscalía Nacional Económica (FNE) es de 114 días naturales (4 meses, aproximadamente) (OECD, 2014). Por otro lado, en Brasil, el Consejo Administrativo de Defensa Económica (CADE) tiene un máximo de 330 días para resolver una operación, expirado ese plazo, la concentración queda aprobada. A lo largo de su historia, menos del $1 \%$ de los casos alcanzaron ese límite y ninguna fue aprobada por este medio. En 2017, la duración promedio fue de 30 días. Incluso, si se diferencia entre los casos que no representan un gran riesgo para la competencia y que por ende se resuelven más rápidamente, de los que requieren mayor investigación, el promedio fue de 15 días para los primeros y 96 para los últimos (OECD, 2019).

Un análisis de estadística descriptiva muestra que, si bien la duración promedio puede dividirse en tres claros períodos, el desvío estándar ${ }^{36}$ mostró un comportamiento creciente a lo largo de casi todos los años. Las únicas excepciones fueron los años 2003, 2005, 2012, 2018 y 2019, donde se redujo respecto al año anterior. El máximo valor de dicho indicador se alcanzó en 2017, el cual fue de 714 días. El hecho de que haya varios años con un alto desvío estándar puede dar cuenta de algunos casos en particular, los cuales fueron más extensos que el resto por su mayor nivel de complejidad o por contar con suspensiones en los plazos.

Con relación a los valores extremos (máximo y mínimo de días de duración), la duración mínima, desde el año 2000, creció un $727 \%$ hasta llegar a su valor máximo de 364 días en 2014. Esto quiere decir que el trámite más rápido de los resueltos en 2014 duró casi 1 año. En particular el valor mínimo ha promediado 119 días a partir de

\footnotetext{
${ }^{33}$ Por lo cual la tendencia lineal presenta un coeficiente de determinación menor $\left(R^{2}=0,46\right)$.

34 La tendencia lineal de la duración promedio anual, estimada para este período, tiene un alto coeficiente de determinación $\left(R^{2}=0,96\right)$, dando una clara indicación del cambio indicado.

${ }^{35}$ El coeficiente de determinación durante este período fue alto $\left(R^{2}=0,91\right)$.

36 El desvío estándar es una medida de cuán lejos del promedio se encuentra la duración de los casos analizados (un desvío estándar de 38 días, como el del año 2000, indica que las operaciones resueltas ese año se alejaron "en promedio" 38 días del promedio, que fue de 103 días). Cuanto más alto el desvío estándar, mayor la dispersión de los datos respecto del promedio (y menos representativo el promedio).
} 
2008, más de tres veces el valor mínimo de los años previos (en promedio entre 2000 y 2007 el mínimo fue de 33 días).

Los valores máximos evidencian una tendencia creciente un poco más larga, ya que recién en 2017 alcanzan su valor tope de 3.336 días (es decir que el trámite más lento de los resueltos en 2017 duró más de 9 años), el cual significa un incremento de más del $1.000 \%$ respecto del 2000 . A partir del 2017, se revierte la tendencia y la cantidad máxima de días comienza a descender.

Se distingue además la gran brecha entre el mínimo y el máximo: de los trámites finalizados en 2017 el más lento duró 3.284 días (8,99 años) más que el trámite más rápido.

Una consecuencia del incremento del desvío estándar y de los valores límites es que a través del tiempo la incógnita que enfrentaron las firmas al planear una operación de fusión o adquisición ha sido más incierta.

En la Tabla 6 se puede observar las tendencias que se mencionaron.

Tabla 6: Indicadores estadísticos de la duración promedio de los trámites de F\&A

\begin{tabular}{|c|c|c|c|c|c|c|}
\hline Año & Casos & $\begin{array}{c}\text { Promedio } \\
\text { (días) }\end{array}$ & $\begin{array}{l}\text { Mínimo } \\
\text { (días) }\end{array}$ & $\begin{array}{l}\text { Máxim } \\
\text { o (días) }\end{array}$ & $\begin{array}{l}\text { Desvío } \\
\text { Estánda } \\
\text { r (días) }\end{array}$ & $\begin{array}{c}\text { Coeficient } \\
\text { e de } \\
\text { Variabilida } \\
\text { d }\end{array}$ \\
\hline 1999 & 7 & 32 & 13 & 52 & 15 & 0,47 \\
\hline 2000 & 161 & 103 & 44 & 282 & 38 & 0,37 \\
\hline 2001 & 99 & 109 & 19 & 325 & 69 & 0,63 \\
\hline 2002 & 25 & 134 & 15 & 435 & 103 & 0,77 \\
\hline 2003 & 40 & 115 & 35 & 306 & 78 & 0,68 \\
\hline 2004 & 43 & 161 & 36 & 749 & 148 & 0,92 \\
\hline 2005 & 43 & 115 & 11 & 475 & 81 & 0,71 \\
\hline 2006 & 61 & 161 & 52 & 439 & 100 & 0,62 \\
\hline 2007 & 34 & 217 & 55 & 459 & 107 & 0,49 \\
\hline 2008 & 38 & 276 & 105 & 987 & 158 & 0,57 \\
\hline 2009 & 46 & 440 & 6 & 939 & 192 & 0,44 \\
\hline 2010 & 43 & 431 & 54 & 1.092 & 259 & 0,60 \\
\hline 2011 & 40 & 543 & 136 & 1.455 & 331 & 0,61 \\
\hline 2012 & 33 & 591 & 156 & 1.111 & 243 & 0,41 \\
\hline 2013 & 41 & 727 & 140 & 1.326 & 313 & 0,43 \\
\hline 2014 & 38 & 962 & 364 & 1.949 & 338 & 0,35 \\
\hline 2015 & 21 & 901 & 198 & 2.535 & 531 & 0,59 \\
\hline 2016 & 108 & 1.113 & 66 & 2.855 & 672 & 0,60 \\
\hline 2017 & 190 & 839 & 52 & 3.336 & 714 & 0,85 \\
\hline 2018 & 147 & 554 & 65 & 2.147 & 451 & 0,81 \\
\hline 2019 & 52 & 472 & 68 & 1.843 & 420 & 0,89 \\
\hline Total & 1.310 & 478 & 6 & 3.336 & 527 & 1,10 \\
\hline
\end{tabular}

Fuente: elaboración propia con datos de la CNDC

Una explicación potencial para el aumento de la duración de los trámites podría ser el incremento de los casos analizados por la CNDC. Sin embargo, el cruce de los datos 
disponibles permite rechazar la hipótesis. La Figura 4 muestra la cantidad de casos evaluados en cada año (eje horizontal) y la duración promedio de los trámites correspondientes (eje vertical): la nube de puntos sugiere que no hay correlación entre cantidad y duración.

Figura 4: Duración promedio según cantidad de casos por año

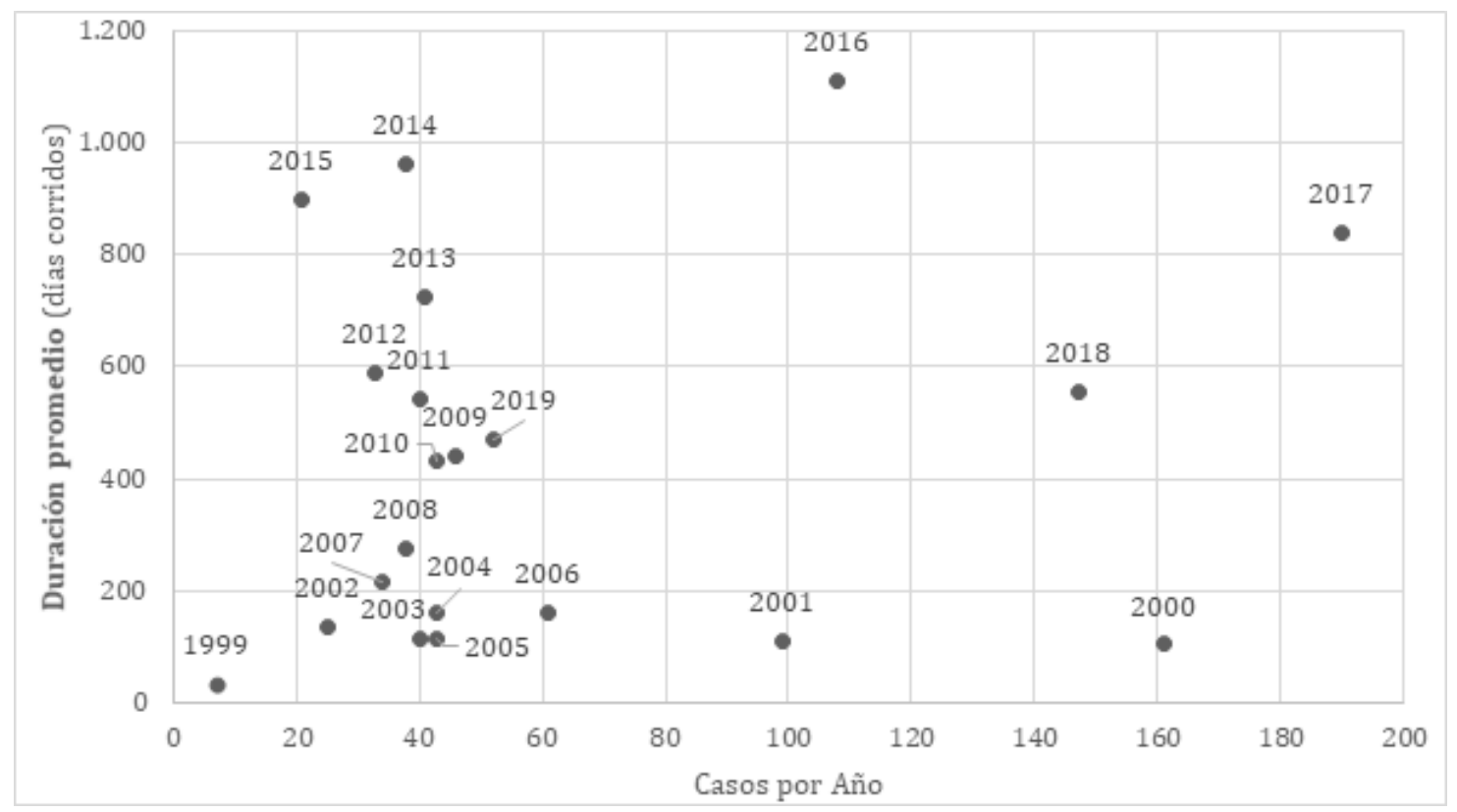

Fuente: elaboración propia con datos de la CNDC

Si bien al analizar los años 2016, 2017 y 2018, se observa que la cantidad de casos es muy grande (108, 190 y 147 respectivamente) y la duración promedio supera a la media del período 1999-2019; los años 2000 y 2001 resultan ser el caso opuesto. Estos últimos años, fueron dos años de mucha cantidad de casos (161 y 99, respectivamente) y sin embargo son los que exhiben la menor duración promedio de los trámites (algo más de 100 días) ${ }^{37}$.

En el resto de los años (2002-2015), la cantidad de casos se mantuvo cercana al promedio de las operaciones evaluadas anualmente (con un mínimo en 2015 de 21 y un máximo en 2006 de 57), pero la duración promedio de los trámites fue muy dispar.

Otra hipótesis explicativa para las diferencias de duración podría ser la naturaleza de las operaciones evaluadas. A priori podría presumirse que las operaciones horizontales, al ser las que generan mayores prevenciones requieren un mayor tiempo de análisis y por lo tanto los trámites durarían más, en promedio, que las verticales, siendo los conglomerados los casos en los que se esperaría una menor duración. Sin embargo, el análisis de los datos contradice esta presunción (Tabla 7): las operaciones horizontales

\footnotetext{
${ }^{37}$ El cambio en la normativa que incrementó los umbrales de notificación de operaciones en marzo 2001 generó una reducción en la cantidad de operaciones que podría generar algún sesgo: si por ejemplo antes del cambio hubiera muchos casos de escasa duración, estos atenúan los efectos de los casos más largos reduciendo de esta forma el promedio de las duraciones. Sin embargo, al tener en cuenta el rango de variación de los valores y el desvío estándar, puede concluirse que este sesgo potencial, sería, en todo caso, de segundo orden de magnitud y no explica las diferencias de duración con años posteriores.
} 
son las que menos duraron, en promedio 464 días, mientras que las verticales 469 días (un $1 \%$ más), y los conglomerados 488 días ( $4 \%$ más que las verticales y $5 \%$ más que las horizontales). Además, se observa que las operaciones mixtas horizontales- verticales son las de mayor duración promedio con 499 días.

Tabla 7: Duración de los trámites de F\&A según naturaleza de la operación.

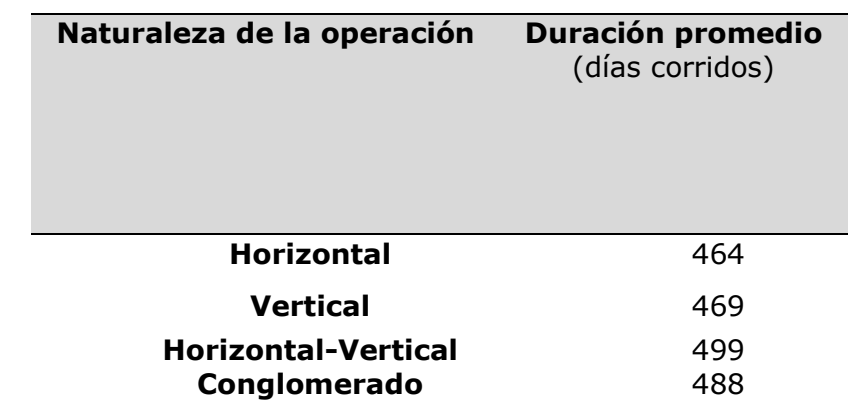

Nota: Horizontal incluye $\mathrm{H}-\mathrm{C}$ y $\mathrm{H}-\mathrm{V}-\mathrm{C}$, mientras que Vertical incluye $\mathrm{V}-\mathrm{C}$

Fuente: elaboración propia con datos de la CNDC

En este sentido, la naturaleza de la operación no logra explicar la dispersión en la duración promedio de los casos a lo largo de los años. De hecho, la distribución de los casos de naturaleza horizontal, vertical, horizontal-vertical y de conglomerado, según su duración es similar (Figura 5).

Figura 5: Distribución de los trámites de F\&A según su naturaleza y duración.

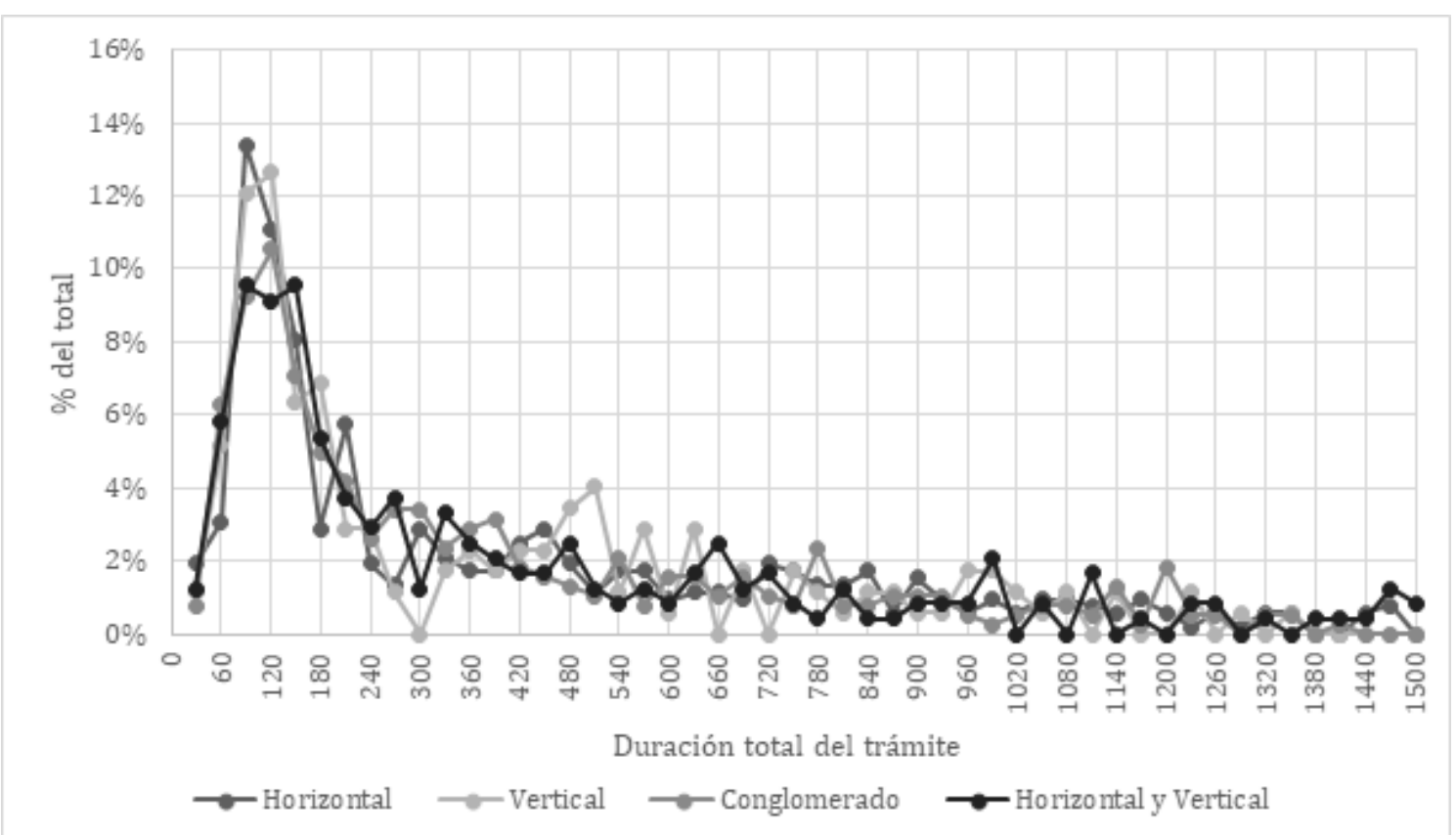

Fuente: elaboración propia con datos de la CNDC

En las cuatro categorías la distribución es asimétrica, con proporciones relativamente altas de los casos concentrados en los rangos de duración entre 30 y 180 días y el resto distribuido en rangos crecientes de duración. 
El análisis cuantitativo es concluyente respecto de que la duración de los trámites de F\&A se encuentra mucho más correlacionada con el paso del tiempo, que con la cantidad de casos o la naturaleza de las operaciones.

En la Figura 6 se representa la distribución (acumulada) de los casos según su duración, separándolos en cuatro períodos: de 1999 a 2008, de 2009 a 2013, de 2014 a 2017 y de 2018 a 2019. Los períodos fueron elegidos considerando los cambios más significativos en la duración promedio de las operaciones (Figura 4).

Figura 6: Distribución acumulada de los trámites de F\&A según su duración. Evolución temporal

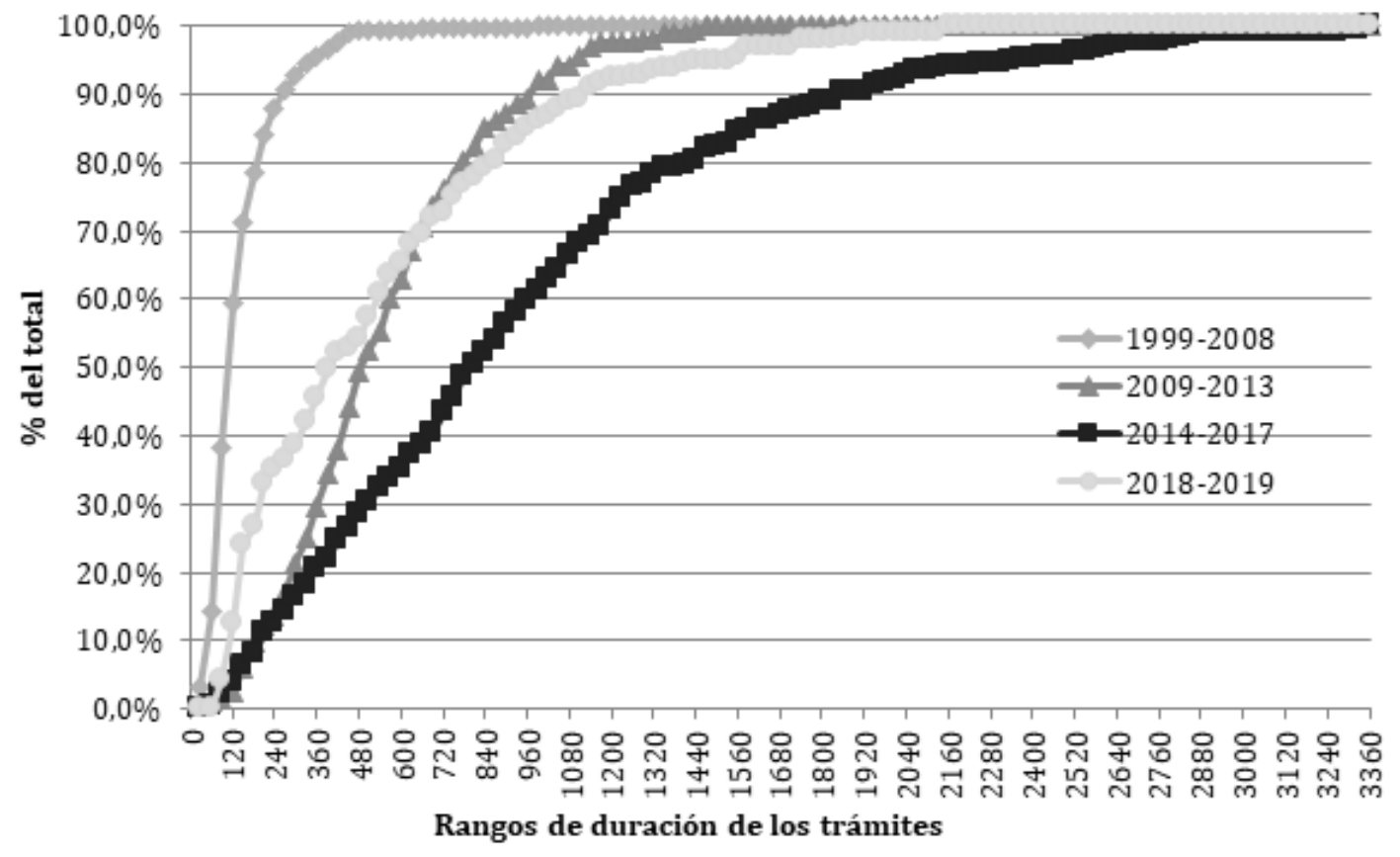

Fuente: elaboración propia con datos de la CNDC

Lo que se puede ver es que entre 1999 y 2008, más del 70\% de los trámites finalizaron antes de los 150 días. Esto contrasta con el resto de los períodos viéndose por ejemplo que entre los períodos 2009-2013 y 2014-2017 los casos con una duración menor a 150 días no superaron el 10\%. En el último período (2018-2019), dicho valor asciende a casi al $24 \%$ de los casos.

Se puede distinguir cómo las curvas referidas a los tres primeros períodos van disminuyendo su pendiente con el cambio del período. Esto indica que la duración promedio total de los casos está en aumento (pudiéndose resolver menos casos en términos relativos a un mismo rango de tiempo en comparación a los períodos anteriores). Recién durante 2018-2019 se logra revertir dicha tendencia.

Un rango relevante para el análisis es el que va desde el inicio hasta los 360 días, ya que indica el porcentaje de casos que no superan una duración promedio de un año. La proporción de casos que no supera el año de duración es de 95,5\% en el primer período (99-08), 29,4\% en el segundo (09-13), 20,4\% entre 2014-2017 (es decir que 
el $79,6 \%$ de los trámites duró más de un año) y 45,7\% en el cuarto período (18-19). En particular, en el tercer período más del $56 \%$ de los casos superó los 720 días (aproximadamente 2 años) de duración. Incluso, casi el $20 \%$ de los casos superó los 1.440 días (aproximadamente 4 años) de duración.

Una nueva hipótesis que se analizó fue si una reducción de los recursos disponibles para la CNDC podría haber incidido en el aumento de la duración de los trámites de F\&A. A tal efecto se estudió la evolución del presupuesto de la CNDC, y se estimó la proporción asignable al análisis de $F \& A^{38}$. El análisis realizado permite rechazar la hipótesis planteada, ya que la relación es inversa a la esperada. Se observa que el mayor aumento de la duración promedio de los trámites (2007-2016) ha sido concomitante con un incremento en el presupuesto medido en millones de pesos en valores de 2003. La Figura 7 muestra la relación entre presupuesto asignado a F\&A (en millones de pesos en valores de $2003^{39}$ ) y la duración promedio de las operaciones por año ${ }^{40}$.

Entre 2003 y 2006 el presupuesto osciló entre 800 mil y 1,5 millones en pesos del 2003, y la duración promedio mostró una leve tendencia creciente (Figura 3). Durante el período de mayor crecimiento de la duración promedio de los trámites (2007-2016), la tendencia del presupuesto es, en su mayor parte, creciente, alcanzando así en 2016 un valor $235 \%$ más elevado en términos reales que en 2007 . No obstante, en ese mismo intervalo de años, la duración promedio llegó a incrementarse más de un $400 \%{ }^{41}$. En contraposición, durante el período 2017-2019, cuando se revierte la tendencia creciente en la duración promedio de los casos, el presupuesto cayó, en términos reales, un $81 \%$ entre los años límite.

\footnotetext{
38 La asignación del presupuesto a fusiones se hizo teniendo en cuenta la participación en el total de las resoluciones de la CNDC de sus dos principales actividades: la evaluación de operaciones de F\&A y la investigación de conductas anticompetitivas. El presupuesto asignado a F\&A se calculó considerando la proporción de resoluciones de F\&A de cada año respecto de la suma total de resoluciones de F\&A y de conductas.

39 Los valores de cada año se actualizaron para ser expresados a precios del 2003, para lo cual se utilizó el Índice de Precios al Consumidor (IPC) de San Luis.

40 Se comienza a partir del año 2003 debido a que durante los años de la crisis el valor asignado de presupuesto es muy distinto al total ejecutado.

${ }^{41} \mathrm{Si}$ se estudia el presupuesto total de la CNDC y no sólo el asignado a F\&A, también hay una relación positiva entre presupuesto y duración.
} 
Figura 7: Duración promedio según presupuesto asignado a F\&A por año

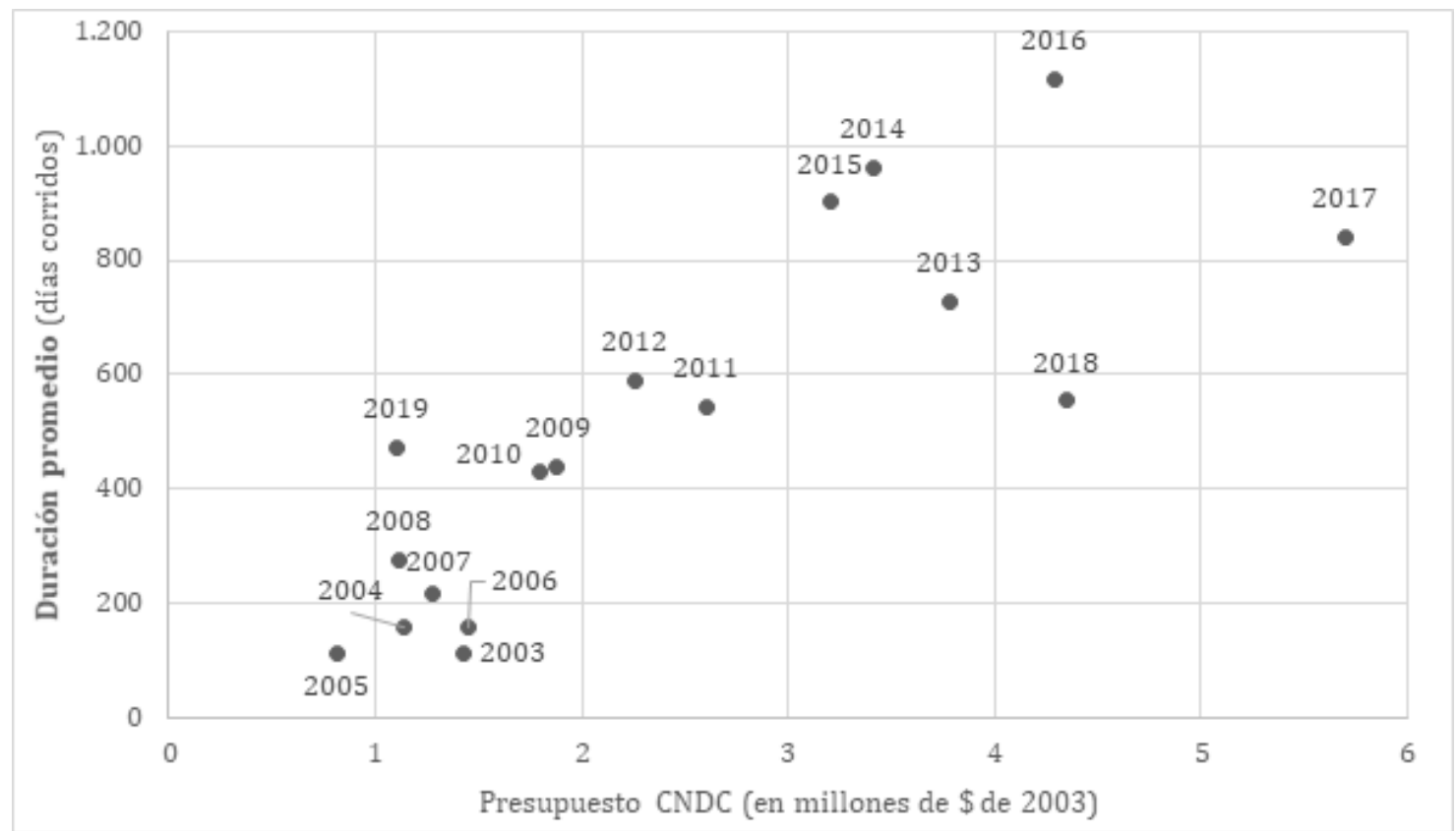

Fuente: elaboración propia con datos de la CNDC y de la Oficina Nacional de Presupuesto

\section{V.3. Análisis de la duración de las fases de evaluación de F\&A}

Al analizar la duración promedio de las distintas fases de evaluación de las operaciones disponibles a partir del año 1999 y hasta el 2019, se puede corroborar una tendencia creciente en todas las fases hasta 2016 (en forma concomitante con el aumento de la duración promedio total indicada anteriormente) y luego una reversión de dicha tendencia. No obstante, existieron particularidades en algunas fases $y$ en ciertos períodos, que se comentan a continuación.

Según se expuso en la sección 2.2, la notificación de una operación ante la autoridad de competencia se inicia con el formulario F1 y por lo tanto es una fase que todas las operaciones deben cumplimentar. En cambio, sólo algunas operaciones pasan a la fase de F2: del total de 1.310 operaciones de las que se computó la duración, 122 presentaron el formulario F2 (9\%). Finalmente, sólo 16 operaciones pasaron a la fase del formulario F3 (1\%).

Según se exhibe en la Tabla 8 , en el período analizado, la duración promedio del F1 aumentó considerablemente pasando de 34 días en el año 2000 a 1.002 días en 2016 (un aumento de $2.847 \%$ ). Este aumento en la duración del $\mathrm{F} 1$ es la que explica en gran medida el aumento de la duración total que se verificó en el período bajo análisis. A partir del 2017, la duración promedio del F1 revierte su tendencia y desciende hasta ubicarse en un valor de 391 en 2019 (una caída de 61\%). 
Tabla 8: Duración promedio de las diversas fases de los trámites de F\&A (días corridos)

\begin{tabular}{ccccccccc}
\hline Año & $\begin{array}{c}\text { Duración } \\
\text { Promedio } \\
\text { F1 }\end{array}$ & $\begin{array}{c}\text { Duración } \\
\text { Promedio } \\
\text { F2 }\end{array}$ & $\begin{array}{c}\text { Duración } \\
\text { Promedio } \\
\text { F3 }\end{array}$ & $\begin{array}{c}\text { Duración } \\
\text { Promedio } \\
\text { Total } \\
\text { Formularios }\end{array}$ & $\begin{array}{c}\text { Duración } \\
\text { Promedio } \\
\text { Dictamen }\end{array}$ & $\begin{array}{c}\text { Duración } \\
\text { Promedio } \\
\text { Resolución }\end{array}$ & $\begin{array}{c}\text { Duración } \\
\text { Promedio } \\
\text { Total }\end{array}$ & $\begin{array}{c}\text { Total } \\
\text { de } \\
\text { Casos }\end{array}$ \\
\hline 1999 & 13 & & & 11 & 14 & 5 & 32 & 7 \\
2000 & 34 & 80 & & 48 & 49 & 5 & 103 & 161 \\
2001 & 48 & 77 & 30 & 66 & 38 & 5 & 109 & 99 \\
2002 & 71 & 58 & 86 & 91 & 23 & 20 & 134 & 25 \\
2003 & 52 & 61 & 119 & 84 & 17 & 14 & 115 & 40 \\
2004 & 81 & 102 & 227 & 129 & 14 & 18 & 161 & 43 \\
2005 & 70 & 67 & & 84 & 15 & 17 & 115 & 43 \\
2006 & 102 & 76 & 57 & 108 & 16 & 38 & 161 & 61 \\
2007 & 155 & 187 & & 172 & 17 & 29 & 217 & 34 \\
2008 & 192 & 346 & & 214 & 20 & 32 & 276 & 38 \\
2009 & 370 & 158 & & 360 & 30 & 36 & 440 & 46 \\
2010 & 354 & 299 & 168 & 379 & 30 & 21 & 431 & 43 \\
2011 & 487 & & & 487 & 33 & 23 & 543 & 40 \\
2012 & 539 & & & 539 & 33 & 19 & 591 & 33 \\
2013 & 646 & 550 & & 673 & 19 & 35 & 727 & 41 \\
2014 & 872 & 694 & & 890 & 40 & 32 & 962 & 38 \\
2015 & 778 & 873 & & 820 & 21 & 59 & 901 & 21 \\
\hline 2016 & 1.002 & & & 1.002 & 53 & 58 & 1.113 & 108 \\
2017 & 736 & 1.191 & & 748 & 45 & 45 & 839 & 190 \\
2018 & 471 & 360 & & 478 & 41 & 35 & 554 & 147 \\
2019 & 391 & & & 391 & 40 & 40 & 472 & 52 \\
\hline Total & $\mathbf{4 0 0}$ & $\mathbf{1 3 8}$ & $\mathbf{1 1 8}$ & $\mathbf{4 1 2}$ & $\mathbf{3 6}$ & $\mathbf{2 9}$ & $\mathbf{4 7 8}$ & $\mathbf{1 . 3 1 0}$ \\
\hline
\end{tabular}

Fuente: elaboración propia con datos de la CNDC

La fase de F2 también mostró una tendencia de crecimiento de la duración pero de menor magnitud (1.388\% entre 2000 y 2017). En particular, en 2011, 2012, 2016 y 2019 no hubo operaciones resueltas que hayan pasado a las instancias de F2 y F3, aun cuando hubo 14 casos con condicionamientos entre los años 2011 y 2012 (9 por cláusula NC, 3 de conducta y 2 estructurales) ${ }^{42}$. Los años 2016 y 2019 no presentaron condicionamientos. La fase de F3, dado que es un formulario ad hoc y que se solicita en pocos casos, su duración fue más errática y mirar el promedio o las tendencias resulta menos informativo.

\footnotetext{
${ }^{42}$ En contraste con el procedimiento establecido en la Resolución SDCC N 40/2001, que requiere el paso por las instancias de F2 o F3 para que la autorización de una operación se subordine al cumplimiento de condiciones (véase sección 2.2. precedente).
} 
Es relevante notar que la columna que indica la duración promedio del total de los formularios en la Tabla 8, no es la suma de las columnas de F1, F2 y F3, ya que en estas 3, difiere la cantidad de casos considerados en el promedio $(1.310,122$ y 16 , respectivamente). Dicha columna indica el tiempo que en promedio demandó la aprobación de los formularios de cada caso, según corresponda, del total de 1.310 casos para los cuales se computó la duración (412 de los 478 días que en promedio requirió la aprobación de todos los 1.310 trámites de fusiones, correspondieron a la fase de formularios).

Las otras fases, el lapso entre el final de la fase de formularios y la emisión del dictamen de la CNDC y la etapa entre dictamen y resolución de la Secretaría correspondiente, muestran un comportamiento diferente. La duración del lapso hasta la emisión del dictamen en promedio no ha crecido. Los dos años con mayor duración fueron 2016 y 2000. En realidad, este período no mide necesariamente el tiempo que demanda la redacción del dictamen, ya que su preparación puede iniciarse en forma simultánea con las fases de formularios. La fase de resolución evidenció un salto en 2002 y 2015: hasta 2001 no superó los 5 días y a partir de 2002 fluctuó en torno a un promedio de 26 días (2002-2014) y 48 días (2015-2019).

\section{V.4. Análisis sectorial de la duración}

En esta subsección se presentan los resultados del análisis estadístico de la duración de los trámites de las operaciones de F\&A desagregadas por sectores económicos. El promedio sectorial de la duración total de los trámites, y el detalle de la duración de las distintas fases de evaluación en el período 1999-2019, pueden verse en la Tabla 9.

Si el análisis se realiza observando los sectores que tuvieron un mayor peso a lo largo años, entre 2001 y 2008, más del $20 \%$ de las operaciones correspondieron al sector de la "Energía", siendo éste uno de los de menor duración promedio. En 2013-2014 el sector de "Combustibles" pasó de representar el 0\% de los casos entre 1999 y 2012, a tener una participación del 15 y $16 \%$ respectivamente. Este hecho no es menor ya que junto con el sector de "Otras Manufacturas" son los de mayor duración promedio. Justamente este último sector, entre 2013 y 2016 representó siempre por lo menos el $5 \%$ de las operaciones, llegando incluso a ser el 21\% de los casos en 2014.

No obstante, una observación que surge del análisis de los datos es que la magnitud de la diferencia de duración entre los distintos sectores es mucho menor que el incremento en la duración de los trámites que se observó en años 2007-2016 (ver Tabla 6). Una conclusión es que los diferenciales de duración intersectoriales son muy inferiores a los intertemporales, es decir que el significativo incremento en la duración de los trámites a partir de 2007 no puede ser explicado por la preponderancia de operaciones de algún sector con trámites particularmente lentos. 
Tabla 9: Análisis sectorial de duración de los trámites de F\&A.

\begin{tabular}{|c|c|c|c|c|c|c|c|}
\hline Sector & $\begin{array}{c}\text { Duración } \\
\text { Promedio } \\
\text { F1 }\end{array}$ & $\begin{array}{l}\text { Duración } \\
\text { Promedio } \\
\text { F2 }\end{array}$ & $\begin{array}{c}\text { Duración } \\
\text { Promedio } \\
\text { F3 }\end{array}$ & $\begin{array}{c}\text { Duración } \\
\text { Promedio } \\
\text { Total } \\
\text { Formularios }\end{array}$ & $\begin{array}{l}\text { Duración } \\
\text { Promedio } \\
\text { Dictamen }\end{array}$ & $\begin{array}{l}\text { Duración } \\
\text { Promedio } \\
\text { Resolución }\end{array}$ & $\begin{array}{c}\text { Duración } \\
\text { Promedio } \\
\text { Total }\end{array}$ \\
\hline Alimentos y Bebidas & 430 & 131 & 11 & 452 & 33 & 26 & 511 \\
\hline Comercialización Minorista y Mayorista & 392 & 178 & 47 & 416 & 39 & 34 & 489 \\
\hline Construcción e Inmobiliario & 440 & 74 & & 431 & 28 & 30 & 509 \\
\hline Energía & 281 & 103 & 74 & 284 & 35 & 30 & 350 \\
\hline Combustibles & 656 & & & 656 & 24 & 36 & 716 \\
\hline Seguros & 531 & & & 531 & 29 & 43 & 603 \\
\hline Medicamentos y Salud & 371 & 279 & 38 & 409 & 28 & 34 & 472 \\
\hline Metalmecánico & 467 & 109 & & 475 & 32 & 24 & 531 \\
\hline Papel, Plásticos y Vidrios & 299 & 46 & 46 & 306 & 22 & 34 & 361 \\
\hline Agricultura, Ganadería y Pesca & 461 & 43 & & 465 & 28 & 30 & 514 \\
\hline Productos Químicos & 569 & 112 & 125 & 592 & 23 & 28 & 643 \\
\hline Servicios Financieros & 280 & 72 & & 284 & 29 & 27 & 340 \\
\hline $\begin{array}{l}\text { Telecomunicaciones, medios de } \\
\text { comunicación y publicidad }\end{array}$ & 216 & 111 & 239 & 249 & 61 & 22 & 331 \\
\hline Transporte y Logística & 451 & 215 & 137 & 466 & 55 & 35 & 556 \\
\hline Arte, Entretenimiento y Recreación & 645 & & & 645 & 62 & 35 & 742 \\
\hline Otras manufacturas & 769 & 618 & & 781 & 29 & 35 & 845 \\
\hline Otros & 381 & 133 & 230 & 391 & 42 & 27 & 459 \\
\hline Total & 400 & 138 & 118 & 412 & 36 & 29 & 478 \\
\hline
\end{tabular}


En este sentido, la causalidad es la inversa, los sectores en los cuales se realizaron proporcionalmente más operaciones de F\&A en los años 2007-2016 son los que en promedio exhiben una mayor duración de los trámites. Por ejemplo, entre dichos años se produjeron un $44 \%$ de las operaciones del sector de "Productos Químicos", más del $50 \%$ de las operaciones correspondientes a los sectores de "Agricultura, Ganadería y Pesca" y "Construcción e Inmobiliario", y el 75\% de las operaciones de "Seguros". Todos estos sectores tienen una duración promedio (643, 514, 509 y 603 días respectivamente) que supera ampliamente el promedio general de todos los rubros (478). De hecho, si no se tuviesen en cuenta dichos sectores, la duración promedio general (1999-2019) sería de 466 días.

Respecto a los cuatro sectores mencionados, "Productos Químicos", "Agricultura, Ganadería y Pesca", "Construcción e Inmobiliario", y "Seguros", si no se consideran los años durante los cuales la duración del proceso aumentó significativamente (20072016), la duración promedio de los sectores hubiese sido notoriamente más baja (370, 452, 176 y 268 días respectivamente)

En el otro extremo, los sectores de "Telecomunicaciones, Medios de Comunicación y Publicidad", "Servicios Financieros", y "Energía" fueron los que mostraron una menor duración promedio de los trámites (331, 340 y 350 días respectivamente). Dichos sectores presentan un porcentaje alto de casos durante el periodo 2000-2006 (68\%, $47 \%$ y $58 \%$ respectivamente) pero bajo durante el período $2007-2016$ (26\%, 29\% y $24 \%$ respectivamente).

Durante el período 2007-2016, la duración promedio de los casos fue de 686 días. Si se ignoran los casos pertenecientes a los sectores de mayor duración promedio ("Productos Químicos", "Agricultura, Ganadería y Pesca", "Construcción e Inmobiliario", y "Seguros"), la cantidad de días se reduce a 673. Por otro lado, si durante el mismo período no se tienen en cuenta los sectores de menor duración promedio ("Telecomunicaciones, Medios de Comunicación y Publicidad", "Servicios Financieros", y "Energía") la cantidad de días aumenta a 710 días.

\section{Conclusiones}

El análisis estadístico de los casos de fusiones y adquisiciones evaluados por la autoridad de competencia argentina entre 1999 y 2019, ha permitido obtener resultados y conclusiones de utilidad, tanto desde el punto de vista de las firmas que planeen operaciones de este tipo, como para la evaluación de desempeño y el diseño de políticas públicas.

La cantidad de operaciones evaluadas por año se redujo luego de los cambios normativos de 2001 y en los últimos años se ha estabilizado con una media de 60 casos por año ${ }^{43}$ entre 2003 y 2019. No obstante, los años 2016, 2017 y 2018

\footnotetext{
${ }^{43}$ Esta es la cantidad de operaciones de las cuales se emitió dictamen y resolución, que puede diferir del número de operaciones notificadas en cada año, dato que no se encuentra disponible.
} 
mostraron un promedio de 148 casos por años. En este sentido, si se ignoran dichos años, el promedio entre 2003-2019 se reduce a 41 casos por año. La mayor parte de las operaciones, casi 3 de cada 5 (57,9\%), fue de naturaleza horizontal, o al menos presentó relaciones horizontales en alguno de los productos involucrados.

La proporción de operaciones de F\&A con algún tipo de acción correctiva, una vez deducidas las que sólo requirieron cambios en las cláusulas NC de los vendedores, osciló en prácticamente todo el período analizado (2000-2015) en el rango de 5\% a $10 \%$, en coincidencia con la experiencia internacional en la materia. No obstante, durante los últimos años, dicho valor se estabilizó en valores muy bajos ( $0 \%$ y $1 \%$ entre 2016-2019).

Las acciones correctivas consistieron en un 38,7\% en condicionamientos de conducta, un $34,4 \%$ en modificaciones de las cláusulas NC y el $26,9 \%$ correspondió a condicionamientos estructurales (desinversiones + denegación de autorizaciones).

De acuerdo con lo que podría esperarse, las operaciones de conglomerado fueron las que mostraron una mayor tasa de autorización sin condiciones $(97 \%)^{44}$, mientras que las horizontales y verticales fueron de $92 \%$ y $94 \%$ respectivamente, y las mixtas horizontales-verticales del $88 \%$. Las operaciones horizontales estuvieron sujetas a igual proporción de condicionamientos estructurales (50\% sacando los casos de cláusula NC) que de comportamiento. En cambio, en las verticales y en las operaciones mixtas (horizontal-vertical), los condicionamientos de conducta fueron más numerosos ( $75 \%$ y $61 \%$, sin cláusula NC, respectivamente).

El resultado más llamativo del análisis realizado se encuentra en el significativo incremento en la duración de los trámites de evaluación de F\&A (2007-2016). El marco normativo fija un límite máximo de 45 días hábiles administrativos para la evaluación de una operación, cumplido el cual quedaría tácitamente autorizada. Sin embargo, la implementación de los procedimientos de evaluación y la evolución en la práctica de las suspensiones de los plazos o del momento en que se comienzan a computar, han implicado que la duración promedio pase de 103 días corridos ( 3 meses) en el año 2000 a 1.113 (más de 3 años) en 2016. Además, el rango de variación se amplió: el desvío estándar fue 38 días en 2000 y de 714 en 2017. El caso de mayor duración en 2000 fue de 282 días ( 9 meses) y en 2017 fue de 3.336 (más de 9 años).

La tendencia de aumento de la duración no fue homogénea, se detecta estadísticamente un cambio con posterioridad a 2006, cuando la tendencia se torna fuertemente creciente, y una reversión de dicha tendencia en 2017.

El análisis estadístico mostró que este crecimiento en la duración no se explica por la cantidad de casos. Esto se debe a que los años con mayor cantidad de casos evidencian desempeños disímiles, y los de baja cantidad relativa presentan una elevadísima dispersión en cuanto a la duración promedio. Tampoco la diferencia en la naturaleza de las operaciones evaluadas explica las tendencias en la duración.

\footnotetext{
${ }^{44}$ De las operaciones de conglomerado observadas a 8 se les requirió modificar la cláusula de No Competencia $(2,1 \%)$ y a 2 se les fijó condicionamientos de conducta $(0,5 \%)$.
} 
Se rechazó también la hipótesis de que fuese una reducción presupuestaria la que pudiera explicar el aumento en la duración de los trámites. De hecho, se observó que la duración promedio aumentó a pesar del aumento del presupuesto en valores reales.

Lo que se corroboró fue que la variable de mayor incidencia en la duración de los trámites de evaluación de F\&A ha sido el paso del tiempo. Entre 1999 y 2008 más del $70 \%$ de los trámites finalizaron antes de los 150 días (5 meses), esta cifra se redujo al $24 \%$ en el lapso 2018-2019. Durante los períodos 2009-2013 y 2014-2017, dicho indicador no superó el $10 \%$.

El análisis de duración también se realizó para las distintas fases del procedimiento de evaluación de F\&A, siendo la fase de formularios (principalmente el F1) la que sufrió un mayor incremento en la duración. La duración de la fase de resolución de los trámites mostró un aumento discreto significativo en 2002 y en 2015 . En el resto de los años se mantuvo relativamente estable.

Complementariamente se realizó un análisis sectorial, que, en primer lugar, dejó en evidencia la utilidad de un estudio más específico para valorar cuantitativamente los antecedentes y su relevancia prospectiva, y en segundo lugar mostró diferencias en los resultados (por ejemplo, en las tasas de condicionamiento) entre sectores. También la duración de los trámites se comportó en promedio divergente entre sectores, aunque en gran medida la explicación se debe al momento en el tiempo en el que se realizaron las operaciones: los sectores con una proporción más alta de operaciones en los años 2007-2016 son los que exhibieron una mayor duración promedio de los trámites.

Finalmente, las grandes variaciones que se han verificado a través del tiempo en los indicadores evaluados, particularmente la duración de los trámites, pero también las tasas de autorización y condicionamiento, los tipos de condicionamiento y las especificidades sectoriales, consolidan la importancia del seguimiento y actualización permanentes del análisis cuantitativo, para poder informar mejor las decisiones, ya sea de las firmas o inversores que evalúen realizar fusiones u operaciones de adquisición de empresas, acciones o activos, o de quienes planifiquen la política de competencia, para evaluar su desempeño y proponer medidas para mejorarlo. 


\section{Referencias}

Barnes, B. G., L. Harp, N. \& Oler, D. (2014). "Evaluating the SDC mergers and acquisitions database". Financial Review, 49(4), 793-822.

Comisión Nacional de Defensa de la Competencia (CNDC) (2002). Memoria Trianual Años 1999/2000/2001.

Comisión Nacional de Defensa de la Competencia (CNDC) (s/f). Memoria Trianual Años 2002/2003/2004.

Comisión Nacional de Defensa de la Competencia (CNDC) (s/f). Memoria anual Año 2005.

Comisión Nacional de Defensa de la Competencia (CNDC) (s/f). Memoria anual Año 2006.

Competition and Markets Authority (2014). Merger inquiry outcome statistics. Government of the United Kingdom, 7/05/2014. Available in: https://assets.publishing.service.gov.uk/government/uploads/system/uploads/attachm ent_data/file/897788/June_2020_-_merger_inquiry_outcome_statistics.csv/preview (consultada el 7 de julio 2020).

Decreto 89/2001. Boletín Oficial de la República Argentina, Buenos Aires, Argentina, 25 de enero de 2001.

Diario Oficial de la Unión Europea (2008) "Directrices para la evaluación de las concentraciones no horizontales con arreglo al Reglamento del Consejo sobre el control de las concentraciones entre empresas" (2008/C 265/07), Comunicaciones e informes, $51^{\circ}$ año, 18/10/2008, 6-25.

Diario Oficial de la Unión Europea (2004). "Directrices sobre la evaluación de las concentraciones horizontales con arreglo al Reglamento del Consejo sobre el control de las concentraciones entre empresas" (2004/C 31/03), Comunicaciones e informes, $47^{\circ}$ año, 5/2/2004, 5-18.

European Commission (2020). Statistics merger cases. Disponible en: https://ec.europa.eu/competition/mergers/statistics.pdf (consultada el 7 de julio 2020).

Graf, C. \& Petrecolla, D. (2011). "Medidas para restablecer la competencia en el análisis de concentraciones". Revista de Derecho Comercial, del Consumidor y de la Competencia, 2(2).

Greco, E. M., Petrecolla, D., Romero, C. A. \& Romero Gómez, E. (2013). "El control de Fusiones y Adquisiciones en Argentina (1999-2011). Indicadores de desempeño". Revista de los Contratos, los Consumidores y Derecho de la Competencia, Año 4-20133.

Ley No 25156 de Defensa de la Competencia. Boletín Oficial de la República Argentina, Buenos Aires, Argentina, 20 de septiembre de 1999. 
Ley $N^{\circ} 27442$ de Defensa de la Competencia. Boletín Oficial de la República Argentina, Buenos Aires, Argentina, 15 de mayo de 2018.

Mulherin, J. H., \& Boone, A. L. (2000). "Comparing acquisitions and divestitures". Journal of corporate finance, 6(2), 117-139.

Netter, J., Stegemoller, M., \& Wintoki, M. B. (2011). "Implications of data screens on merger and acquisition analysis: A large sample study of mergers and acquisitions from 1992 to 2009". The Review of Financial Studies, 24(7), 2316-2357.

Organization for Economic Cooperation and Development (OECD) (2006). Derecho y Política de la Competencia en Argentina. Banco Interamericano de Desarrollo \& Organización para la Cooperación y el Desarrollo Económicos.

Organization for Economic Cooperation and Development (OECD) (2010). Standard for Merger Review 2009.

Organization for Economic Cooperation and Development (OECD) \& Banco Interamericano de Desarrollo (2006). Competition Law and Policy in Latin America.

Organization for Economic Cooperation and Development (OECD) (2014). Evaluación del Régimen de Control de Concentraciones en Chile. Informe del Secretariado de la OCDE

Organization for Economic Cooperation and Development (OECD) (2018). OECD Peer Reviews of Competition Law and Policy: Viet Nam.

Organization for Economic Cooperation and Development (OECD) (2018). OECD Peer Reviews of Competition Law and Policy: Greece.

Organization for Economic Cooperation and Development (OECD) (2018). OECD-IDB Peer Reviews of Competition Law and Policy: Peru.

Organization for Economic Cooperation and Development (OECD) (2019). OECD Peer Reviews of Competition Law and Policy: Brazil.

Organization for Economic Cooperation and Development (OECD) (2020). OECD Peer Reviews of Competition Law and Policy: Mexico.

Petrecolla, D. \& Bidart, M. (2007). "Competencia y regulación: el bloqueo de la venta del concesionario del Correo Oficial (2000-2001)". Revista de la Competencia y la Propiedad Intelectual, 3(4).

Petrecolla, D. \& Romero, C. A. (2010). "El control de concentraciones en el sector de generación eléctrica". Revista de la Competencia y la Propiedad Intelectual, 6(11).

Petrecolla, D., \& Ruzzier, C. (eds.) (2004). Problemas de Defensa de la Competencia en Sectores de Infraestructura en la Argentina. Ciudad Autónoma de Buenos Aires: Temas Grupo Editorial SRL.

Resolución SCDDC N¹64/2001. Boletín Oficial de la República Argentina, Buenos Aires, Argentina, 30 de noviembre de 2001. 
Resolución SDCC N 40/2001. Boletín Oficial de la República Argentina, Buenos Aires, Argentina, 26 de febrero de 2001.

Resolución SICM No 726/1999. Boletín Oficial de la República Argentina, Buenos Aires, Argentina, 26 de septiembre de 1999.

United Nations Conference on Trade and Development (UNCTAD) (2018). Voluntary Peer Review on Competition Policy: Botswana (UNCTAD/DITC/CLP/2018/1).

United Nations Conference on Trade and Development (UNCTAD) (2017). Voluntary Peer Review on Competition Policy: Argentina (UNCTAD/DITC/CLP/2017/1).

United Nations Conference on Trade and Development (UNCTAD) (2016). Voluntary Peer Review on Competition Policy: Uruguay (UNCTAD/DITC/CLP/2016/1). 